\title{
INFERÊNCIAS SOBRE O USO DE GRAFENO EM MATERIAIS COMPÓSITOS COM ÊNFASE EM MATERIAIS À BASE DE POLIPROPILENO
}

\author{
Daniel Carlos Martins dos Santos ${ }^{1}$
}

RESUMO: O presente trabalho tem a intenção de apresentar parâmetros e comparar a viabilidade do uso de grafeno em materiais reciclável, com ênfase no polipropileno, quanto a sua melhoria na matriz e utilização na construção civil. Será abordado os conceitos sobre o que é o grafeno, assim como os métodos para obtenção, as áreas de utilidade, o desenvolvimento dele no Brasil e materiais atuais que já utilizam essa forma de carbono. $O$ Grafeno tem-se mostrado um material promissor devido as suas características e propriedades físicas e químicas. Em tempos atuais, manifesta-se a curiosidade de compreender a abrangência de sua utilização. Segundo Alexandre Formigoni (2012), O crescimento da população e o estímulo ao consumo de produtos industrializados descartáveis têm aumentado a quantidade e a diversidade dos resíduos urbanos. Em continuidade fala que a simples disposição dos resíduos industriais, comerciais e domésticos urbanos em aterros sanitários fez com que eles estejam em vias de saturação. Desta forma, o objetivo dessa pesquisa é especificamente identificar as atuais utilizações do grafeno e seus derivados para aperfeiçoamento das propriedades mecânicas de materiais compósitos, fazendo uma inferência do módulo de Young do composto reforçado de derivados do grafeno em relação ao aço e abordar sobre o preço aquisitivo do grafeno brasileiro com base nas tecnologias atuais. A pesquisa foi desenvolvida por meio do método dedutivo, com base em estudos de bibliografias na qual se pode obter um resultado inesperado, porém positivas do que se era esperado. Foi estruturada por meio de um estudo teórico que consiste em utilizar livros acadêmicos, revistas eletrônicas, leis, dentre outras fontes científicas como fundamento conceitual.

Palavras Chave: Grafeno. Compósito. Polipropileno.

ABSTRACT: The present work intends to present parameters and compare the feasibility of using graphene in recyclable materials, with an emphasis on polypropylene, regarding its improvement in the matrix and use in civil construction. The concepts of what graphene is, as well as the methods for obtaining it, the areas of utility, its development in Brazil and current materials that already use this form of carbon will be addressed. Graphene has shown itself to be a promising material due to its physical and chemical characteristics and properties. Nowadays, there is a curiosity to understand the scope of its

\footnotetext{
I Engenharia Civil pela Faculdade de Tecnologia e Ciências (2020). Atuou como Monitor na disciplina de Calculo II e Concreto Armado I Atuou como Representante do Curso de Engenharia Civil no Crea-Jr Atuou em ações sociais oferecidas pela UniFTC Itabuna Atuou dando banca na disciplina de Cálculo II Tem experiência na área de Engenharia Civil, com ênfase em Construção Civil. Pós Graduado em Geotecnia e em Eng. de Avaliação e Perícia.
} 
use. According to Alexandre Formigoni (2012), Population growth and encouraging the consumption of disposable industrialized products have increased the quantity and diversity of urban waste. He goes on to say that the simple disposal of industrial, commercial and domestic urban waste in landfills has caused them to be saturated. Thus, the objective of this research is specifically to identify the current uses of graphene and its derivatives to improve the mechanical properties of composite materials, making an inference of the Young's module of the reinforced compound of graphene derivatives in relation to steel and addressing the price acquisition of Brazilian graphene based on current technologies. The research was developed through the deductive method, based on studies of bibliographies in which an unexpected result can be obtained, but positive than was expected. It was structured through a theoretical study that consists of using academic books, electronic journals, laws, among other scientific sources as a conceptual foundation.

Keywords: Graphene. Composite. Polypropylene,

\section{INTRODUÇÃO}

Desde a última revolução industrial (também chamada de revolução informacional) que, segundo SOUZA (2020), teve início em I95o e dura até os dias atuais, é o marco da modernização das indústrias e evolução tecnológica na qual é reconhecida hoje. Historiadores acreditam que o impulso que resultara ao início desse novo ciclo da revolução, foi causado pelo desenvolvimento tecnológico militar na Segunda Guerra Mundial em diferentes áreas da engenharia, exemplos dessa tecnologias (citada em um artigo do site "Tecmundo" com o título: 8 Tecnologias inventadas para a guerra que fazem parte do nosso cotidiano, em 2013) são: Forno Micro-ondas, GPS, Câmeras Digitais, Controle de Tráfego Aéreo, Antibióticos (penicilina), Serviços de Ambulância, Computadores e Internet.

Desde então, quando se iniciou em 1950 a mais nova fase da revolução industrial, o aperfeiçoamento das tecnologias permitiu a modernização na construção civil. A última década do século XX foi marcada pela consolidação e crescimento vertiginoso de uma nova área do conhecimento, que trouxe no seu bojo a promessa de uma verdadeira revolução científica e tecnológica, derrubando antigos paradigmas, abrindo novos horizontes e rompendo fronteiras estabelecidas entre disciplinas: a nanociência e nanotecnologia (ZARBIN, Aldo; OLIVEIRA, Marcela 2013).

Mas o que seria a nanociência e a nanotecnologia? E a resposta, segundo o CETENE (Centro de Tecnologias estratégicas do Nordeste), é que "a nanotecnologia é o estudo de manipulação da matéria em escala atômica e molecular e incluí o 
desenvolvimento de materiais que está associada a diversas áreas como a medicina, eletrônica, ciência da computação, física, química, biologia e engenharia dos materiais entre outras. A atuação nessas áreas tem como princípio básico a construção de estruturas e novos materiais a partir dos átomos onde o objetivo principal não é chegar a um controle individual dos átomos, mas elaborar estruturas estáveis com eles”

Nos tempos atuais, duas questões são constantemente debatidas: eficiência energética e preservação ambiental. A crescente demanda do consumo de energia mundial exige o desenvolvimento de sistemas e dispositivos de alto desempenho que possibilitem um consumo mais eficiente, além de evitar danos ao meio ambiente e esgotamento de recursos a longo prazo, Materiais à base de carbono têm sido o foco de diversos estudos recentes visando aplicações eletroquímicas, em virtude de suas propriedades, estrutura e abundância juntamente com o fato de serem ambientalmente benignos. Dentre esses materiais destaca-se o grafeno, alótropo mais recente do carbono (J. E. D.Vieira, E. O. Vilar).

Consoante do conceito de desenvolvimento sustetável em que devemos conservar recursos naturais para garantir o futuro das próximas gerações, se faz necessário desenvolver tecnologias inovadoras como alternativa de reutilizar o lixo gerado e lançado irregularmente na natureza. É notorio que a ação humana tem causado um desequilibrio em diversos ecossistemas naturais, por conta disso, um dos meios escolhido para uma diminuição de impacto ambiental foi o fim dos lixões a céu aberto e reforço nas políticas de reciclagem. Consequentemente, os produtos recolhidos via reciclagem serão encaminhado para processo de reutilização, e surgirá uma necessidade de destinação dos mesmo, tendo como um possível caminho para o reuso desses materiais a construção civil.

Em tese, as propriedades do grafeno possibilita aos materiais alterações em sua estrutura molecular gerando um novo tipo de composito resistente. Estudar essa possibilidade de utilização em materiais recicláveis, promete revolucionar a construção civil com estruturas mais leves, extinção de uma das principais patologias que é a corrosão e enfraquecimento da armadura, vigas com menores dimensões e maiores extensões.

Portanto, essa pesquisa buscou identificar as possibilidades do uso do grafeno e seus derivados, em materiais polipropileno, fazendo uma inferência do módulo de Young do novo material e do preço aquisitivo do grafeno brasileiro. 


\section{REFERÊNCIAL BIBLIOGRÁFICO}

\section{I O que é o grafeno?}

Segundo Carvalho, apoiado também pelo artigo publicado pelo nobelprize.org, o grafeno consiste de uma camada muito fina do grafite, facilmente encontrado em ponta de lápis de escrever, e o que difere o grafeno do grafite é que o mesmo possui uma estrutura hexagonal cujos átomos individuais estão distribuídos, gerando uma única e fina camada de carbono, ou seja, o que constitue o grafite são várias camadas sobreposta como uma espécie folhas de carbono, que quando separada apenas uma das "folhas" de carbono, tem-se então o grafeno (GUADALUPE 2012).

Figura I - Estrutura Hexagonal do Grafeno

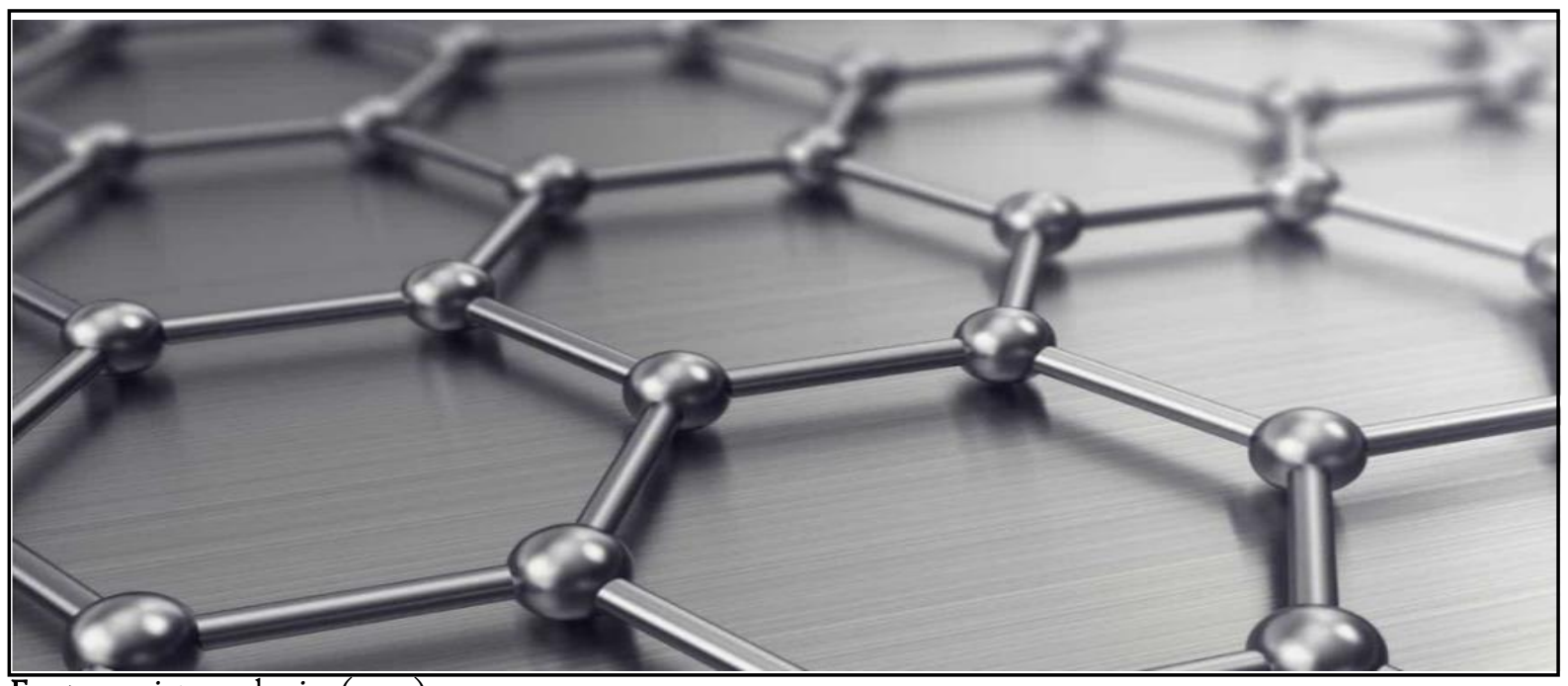

A estrutura hexagonal do grafeno (como mostra na Figura I) é composto por átomos de carbono fortemente ligado entre si permitem uma gama de propriedade, sendo elas mecânicas, eletrônicas e química (MA. GUADALUPE 2012). Ainda sobre sua estrutura molecular, ALDO J. G. (2013) destaca que, a forma em que os carbonos são organizados podem originar outros materiais tendo como exemplo o diamante e grafite, entretanto, com recentes estudos e manipulação do grafeno, derivou-se outras estruturas com propriedades diferentes, sendo elas o nanotubo de grafeno e o fulereno. 
Até agora, as propriedades elétricas colocam o grafeno no auge dos novos materiais,e por apresentar menor problema de toxicidade é um componente chave para a substituição do silício na área dos eletrônicos (MA. GUADALUPE 2012).

\section{I.I Aplicação do grafeno}

Ainda a um mistério a cerca da total capacidade e aplicação do grafeno, mas, estudos atuais já tem uma previsão para aplicações em (I) compositos, (II) energia, (III) sensores e biosensores, (IV) eletrônica, (V)filmes finos, (VI) meio ambiente (ALDO J. G 2013).

(I)A área dos materiais compositos sem dúvidas será uma das mais beneficiada, devida a alta razão Compimento/Diâmetro dos nanotubos. Compositos são um tipo de material originado da combinação de diferentes materiais, gerando uma espécie de materiais com propriedades únicas, são exemplo de compósitos o concreto, madeira, tinta e fibras de vidro. Em diferentes obras na construção civil que se aplica o concreto, o problema mais recorrente é o indicie vazios, que pós cura, acarreta enfraquecimento e fenômenos de exsudação (subida da água), O acrescimo do nanotubos de grafeno à composição do concreto, permitirar o preenchimento dos vazios devido a sua estrutura nanométrica, garantindo um concreto mais resistente (SILVA MELO,2009).

(II) As diversas aplicabilidade do grafeno na área da energia, vai desde o armazenamento, como nas baterias de celular e notebook que são utilizados iões de lítio, na contrução de novos paineis solares, etc (Assunção 2016). A estrutura molecular do grafeno permite uma melhor condutividade e passagem de eletrons sem alta resistência, o que possivelmente, despresa a perda de energia em calor durante a passagem dos elétrons, trazendo maior eficiência na capitação e armazenagem.

(III) Entre as possíveis aplicações do grafeno como materiais $2 \mathrm{D}$, estão surgindo sensores e biossensores, devido às excelentes propriedades elétricas e ópticas desses materiais, recentemente mostrando um grande potencial em bioquímica e nanomedicina (Chen et al., 2015a, 2015b; Tan et al., 2013). Segundo Paolo Bollella et al (2016), essas aplicações do grafeno, mais precisamente o dióxido de grafeno, servirá para identificar com maior precisão tipos de doença ou agente químicos e/ou biológicos.

(IV) A condutividade térmica do grafeno em temperatura ambiente pode 
atingir $5000 \mathrm{~W} / \mathrm{m} . \mathrm{K}$ (para comparação, a do cobre é $400 \mathrm{~W} / \mathrm{m} . \mathrm{K}$ ), J. E. D.Vieira (2017). Segundo Rafael Helerbrock, em uma artigo publicado no site “mundoeducacao.bol.uol.com.br", a resistividade do grafeno tem uma grandeza de $10^{-6} \Omega . m$ , muito menor que a da prata que até então tinha a menor resistividade entre os materiais metálicos, seguindo a premissa dos principios das Leis de Ohn, o material por apresentar uma menor resistividade, possibilitará a melhor passagem de eletróns evitando perdas em calor, consequentementemente, produtos como processadores descartariam o uso de coolers para resfriação.

(V) Em relação aos filmes finos Aldo J. G. Zarbin (2013) fala sobre a ultilização em touch screen, Led's, células solares flexíveis e transparente. Alguns videos promocionais do grafeno, reforça seu uso para armazenamento de energia em uma fina camada de células transparente e flexivel sobre a pele, devido ao movimento do corpo.

(VI) O tratamento de poluentes da água, incluindo efluentes industriais nocivas, descarga agrícola, resíduos domésticos, e microrganismos patogênicos estão sendo pesquisados em todo o mundo (Lara De Souza Soletti et al, 2019). Métodos avançados auxiliados pela nanotecnologia, como filtração por membrana, osmose reversa, fotocatálise heterogênea, ozonização etc. estão sendo estudados no tratamento e reciclagem de águas residuais (DAMODAR et al., 2009).

\subsubsection{Formas de obtenção do grafeno}

A fabricação do grafeno em grande escala tem sido um empecilho para sua aplicação em produtos ao público. POTTS (20II) afirma que em 40 anos de estudo do grafeno, pode-se obter o grafeno puro e praticamente livre de defeitos e com propriedades físicas excepcionais por métodos como o crescimento por deposição de vapor químico, esfoliação micromecânica de grafite e crescimento em carboneto de silício cristalino. Destaca-se ainda que existe diferentes métodos para obter-se o grafeno, entretanto, para uma mais breve compreensão enumera-se os seguintes métodos:

- Deposição química na fase vapor (CVD): segundo HACK (2013) o CVD ( Chemical Vapor Depoisition) é um método que consiste no crescimento de filme de grafeno em uma superfície metálica que será aquecida em temperaturas relativamente alta onde o carbono é aquecido dissolvendo-o no metal e resultará em uma solução sólida. Por 
conseguinte, a placa é resfriada até uma temperatura de $800{ }^{\circ} \mathrm{C}$ onde o carbono reduzirá sua solubilidade e passará a leva-lo para a superfície, logo após, o sistema é resfriado rapidamente até atingir a temperatura ambiente onde o grafeno se desprenderá como observado na Figura (2).

Figura 2 - Processo para obtenção do grafeno por Deposição química na fase vapor

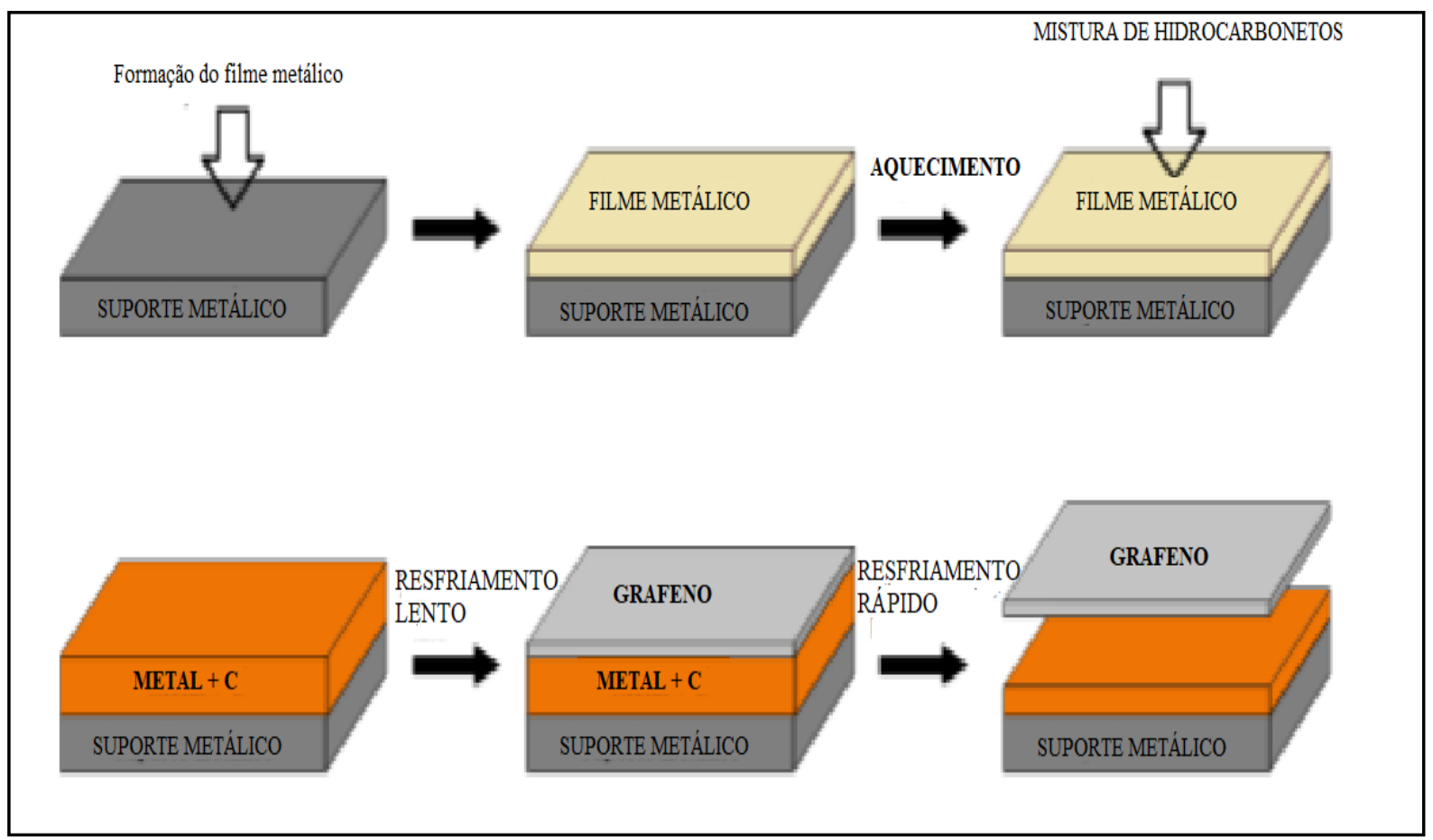

Fonte: Adaptada de ZHANG \& FENG (2010)

- Esfoliação mecânica do grafite: Em 2004, o grafeno foi obtido por separação mecânica de folhas de grafeno em camadas individuais a partir de pequenas placas de $\mathrm{Imm}$ de espessura de grafite pirolítico altamente orientado (J. E. D.Vieira, 2017). consiste basicamente na retirada das camadas do grafite, comumente é utilizado o HOPG (Highly oriented pyrolytic graphite que em português significa grafite pirolítico altamente orientado), por meio de uma fita adesiva (OLIVEIRA, 2017).

- Redução do óxido de grafite: Segundo SCHNIEPP et al (2006), A obtenção de folhas de grafeno a partir do óxido de grafite (GO) vem sendo um dos métodos mais promissores, pois apresenta um potencial para produção em maior escala, destacando-se também pelo baixo custo já que despensa o uso de maquinário e reagentes de elevado valor. A produção de grafeno por redução química de óxido de grafeno (rGO) envolve três etapas 
gerais; a primeira é a oxidação do grafite, seguida de dissolvimento em água, tornando a esfoliação subsequente em camadas individuais relativamente fácil por sonicação por ultrassom da solução aquosa, após a reação de redução, o rGO é lavado com água destilada para remover resíduos da solução redutora e seco por 3 horas em um forno a vácuo a $80^{\circ} \mathrm{C}$ (Carlos A. Guerrero Salazar et al ,2019).

Negreti 2016, traz em sua dissertação, apresentações de alguns métodos existente, assim como suas vantagens e as desvantagens, identificados no quadro I.

Quadro I - Método de obtenção de grafeno

\begin{tabular}{|l|l|l|l|l|}
\hline Método & Espessura & Comprimento & Vantagem & Desvantagem \\
\hline CVD & $\begin{array}{l}\text { Poucas } \\
\text { camadas }\end{array}$ & Cm & $\begin{array}{l}\text { Grande } \\
\text { comprimento; } \\
\text { alta qualidade }\end{array}$ & $\begin{array}{l}\text { Baixa } \\
\text { produção }\end{array}$ \\
\hline Descarga de arco & $\begin{array}{l}\text { Monocamada, } \\
\text { bicamada } \\
\text { poucas } \\
\text { camadas }\end{array}$ & $\begin{array}{l}\text { Entre Ioonm e } \\
\text { alguns } \mu \mathrm{m}\end{array}$ & $\begin{array}{l}\text { Produção de } \\
\text { Io g/h }\end{array}$ & $\begin{array}{l}\text { Impurezas } \\
\text { carbonáceas }\end{array}$ \\
\hline $\begin{array}{l}\text { Crescimento } \\
\text { epitaxial em SIC }\end{array}$ & $\begin{array}{l}\text { Poucas } \\
\text { camadas }\end{array}$ & Até cm & $\begin{array}{l}\text { Grande área } \\
\text { de grafeno } \\
\text { puro }\end{array}$ & $\begin{array}{l}\text { Baixa } \\
\text { produção }\end{array}$ \\
\hline Descompactação & $\begin{array}{l}\text { Múltiplas } \\
\text { camadas }\end{array}$ & Alguns $\mu \mathrm{m}$ & $\begin{array}{l}\text { Tamanho } \\
\text { controlado de } \\
\text { acordo com os } \\
\text { NTC } \\
\text { partida } \\
\text { de }\end{array}$ & $\begin{array}{l}\text { Matéria prima } \\
\text { carajafeno } \\
\text { oxidado }\end{array}$ \\
\hline
\end{tabular}




\begin{tabular}{|l|l|l|l|l|}
\hline Redução de CO & $\begin{array}{l}\text { Múltiplas } \\
\text { camadas }\end{array}$ & Até $\mu \mathrm{m}$ & $\begin{array}{l}\text { Folhas sem } \\
\text { oxidação }\end{array}$ & $\begin{array}{l}\text { Contaminação } \\
\text { com } \alpha-\mathrm{Al}_{2} \mathrm{O}_{3} \text { e } \\
\alpha-\mathrm{Al}_{2} \mathrm{~S}\end{array}$ \\
\hline
\end{tabular}

Fonte: Adaptado Negreti, (2016)

\subsubsection{Grafeno no Brasil}

O Brasil não faz parte do grupo de pioneiros no ramo do grafeno, entretanto, a Companhia de Desenvolvimento Econômico de Minas Gerais (CODEMIG) buscou parceria com o Centro de Desenvolvimento da Tecnologia Nuclear (CDTN) e com a UFMG para desenvolver a tecnologia de produção do grafeno, em escala piloto (Oliveira, 2017).

Embora tenha destaque no quesito ciência, o país está muito atrasado em relação a patentes e a tecnologia. A base de dados do INPI registra apenas 57 patentes contendo nanotubos de carbono no título ou resumo, e míseras 3 ocorrências com grafeno. Dados não-oficiais estimam que o Brasil hoje produz aproximadamente 300 produtos de base nanotecnológica (este número é bastante contraditório, podendo chegar a 70o), e aparentemente nenhum baseado em nanoestruturas de carbono (ALDO J. G. ZARBIN; MARCELA M. OLIVEIRA, 2013).

Esta realidade deve mudar em breve, com a efetivação do CT-Nanotubos, um projeto de pesquisadores da UFMG, com apoio da Petrobras, BNDES, e dos governos municipal de Belo Horizonte e estadual de Minas Gerais, que visa a construção, no parque tecnológico de Belo Horizonte (BH-Tec), de um espaço destinado à fabricação em escala pré-industrial de nanotubos de carbono (ALDO J. G. ZARBIN; MARCELA M. OLIVEIRA, 2013).

Em Abril de 2020, foi divulgado no site "pioneiro.clicrbs.com.br/" a inauguração da maior fábrica de grafeno da America Latina, UCSGraphene (ou TECNOUCS, da Universidade de Caixias do Sul (UCS)), destacada na figura 3. Com estimativa de produção de até $42 \mathrm{Kg}$ por mês e até $500 \mathrm{Kg}$ por ano. Algumas das aplicações do grafeno já pesquisadas, já estão em pleno funcionamento, sendo ela para: Tintas, cerâmicas, medicina regenerativa, coletes a prova de bala e capacetes. 
Diego Mandarino, um dos autores do site "pioneiro.clicrbs.com.br", divulgou em feveireiro de 2020, uma entrevista com o reitor da UCS, Evaldo Kuiava, abordando o uso do grafeno em: tintas na pintura de cascos de navios, construção civil, fabricação de plásticos e painéis solares. Neste aspecto dando ênfase a citação anterior Kuaiava em uma entrevista realizada no ano de 2020 fala:

Nós temos já clientes fora da região que estão demandando para aplicar em polímeros plásticos, por exemplo. Temos uma indústria de polímeros, de plásticos, enorme em Caxias do Sul, com grande potencial. Para pintar cascos de navio, por exemplo, temos uma demanda de clientes que estão procurando porque a corrosão é muito grande. A tinta com grafeno evita essa corrosão, e a manutenção é muito mais fácil. Os sedimentos do mar, por exemplo, com a tinta a base de grafeno, têm dificuldades de grudar no casco. Evaldo Kuiava, 2020

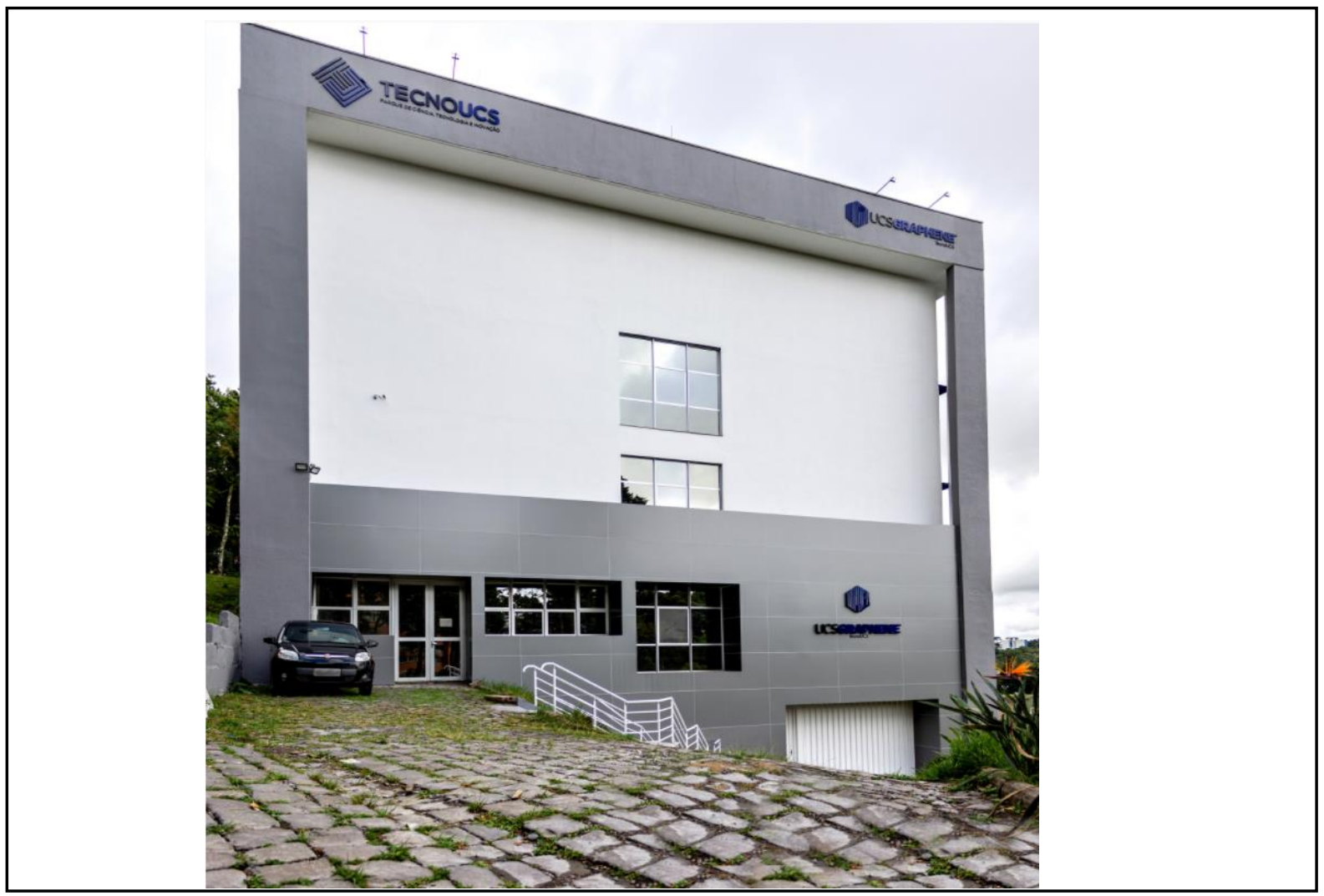

Figura 3 - Fábrica TECNOUCS, da Universade de Caixias do Sul (UCS)

Fonte: ucsgraphene, (2020)

\subsubsection{Uso do grafeno em compósitos}

Um material compósito ou simplesmente "compósito" consiste na união física de dois ou mais materiais com propriedades físicas e químicas diferentes, mas quando 
combinados, eles produzem um novo material com características muito diferentes das originais (Carlos A. Guerrero Salazar et al, 2019). Segundo Carlos A. Guerreiro Et Al (2019), um material compósito se caracteriza por conter pelo menos uma parte matricial e outra fase dispersa nele considerada como um reforço, o material usado como matriz pode ser um polímero, um metal ou uma cerâmica e a fase dispersa pode estar na forma de partículas, fibras, flocos, etc.

Anabele M. Moreira; (2009) confirma ao falar que os materiais compósitos podem ser definidos como misturas (ao nível macroscópico) não solúveis de dois ou mais constituintes com distintas composições, estruturas e propriedades que se combinam e em que um dos materiais garante a ligação - matriz - e o outro a resistência - reforço

$\mathrm{Na}$ figura 4, a parte em vermelho destaca uma partícula inserida em matriz polimérica, a adição de particular em materiais polimérico altera suas características físicas afetando o módulo de Young do material. O módulo de Young é a constante de proporcionalidade que foi calculado no início do século XIV por Thomas Young, razão pela qual recebeu esse nome, o módulo corresponde à constante de proporcionalidade que relaciona a tensão e a deformação da unidade (desde que o material não exceda seu limite elástico), e pode alterar de acordo com a temperatura (J.A Rayas et al,2003).

Figura 4 - Microscopia (através de microscópio electrónico de alta resolução) da estrutura de um material compósito.

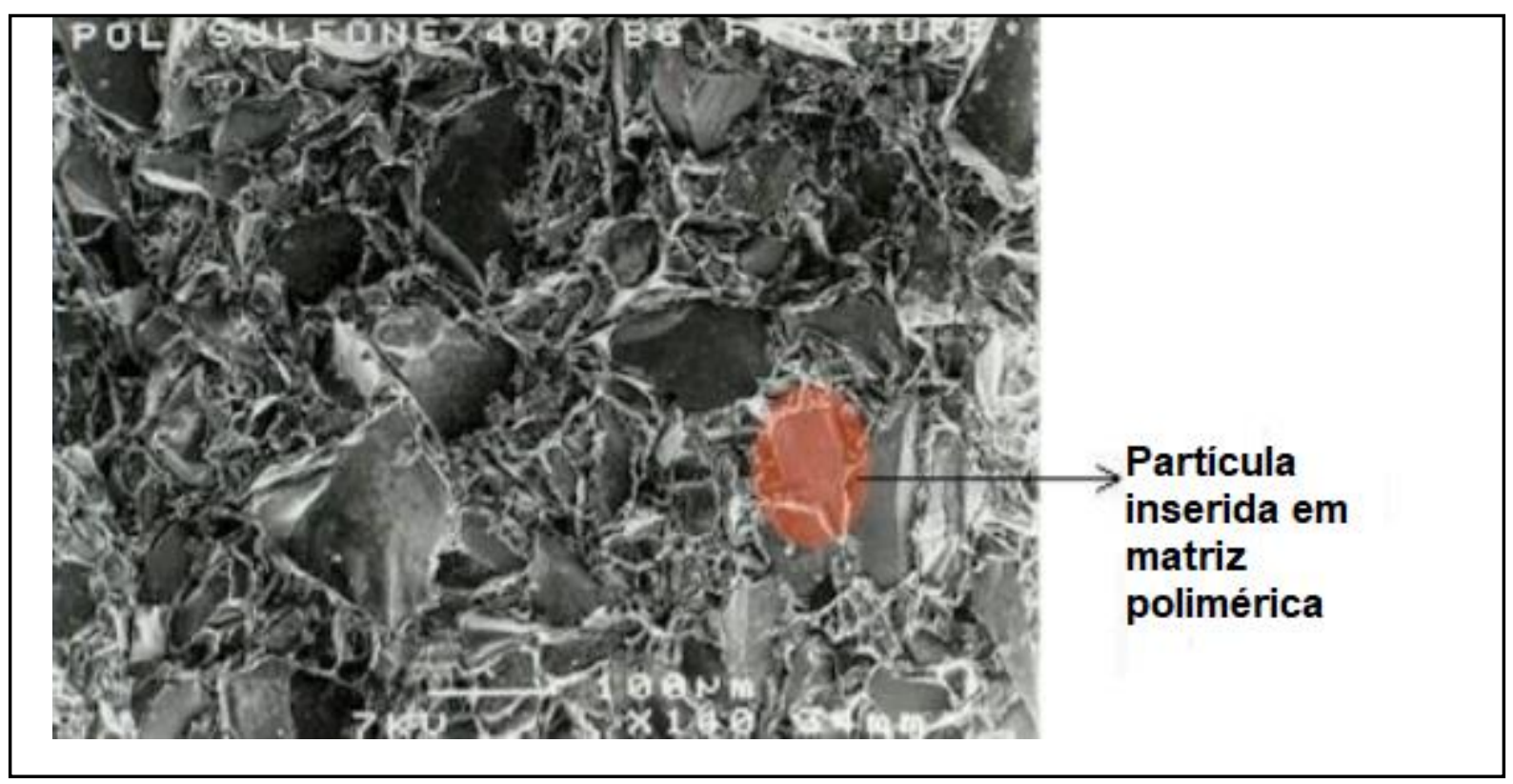


Fonte: Adaptado MOREIRA, (2009)

\subsection{Termoplásticos}

Os termoplásticos, são plásticos que, quando submetido a altas temperaturas aumenta sua viscosidade tornando-o mais fluído, quando ocorre o resfriamento desses materiais ele diminuí a sua viscosidade e se torna mais solido assumindo a forma do molde anteriormente submetido.

São exemplos de termoplásticos: o polimetil-metacrilato (popularmente conhecido como acrílico), policloreto de vinil (o PVC), o polietileno, o polipropileno, entre outros. Os materiais Termoplásticos são ideais para reciclagem devido a sua característica de remodelação e capacidade de fundir-se com outros materiais de reforços matriciais com o aumento da temperatura, diferente dos termofixos que não alteram a suas características quando o mesmo ocorre com eles, podendo até se decompor, mas nunca se fundir. $\mathrm{Na}$ figura 5, observa-se os diferentes tipos de plásticos, seguido por seu número e siglas identificadoras.

Figura 5 - Tipos de termoplásticos

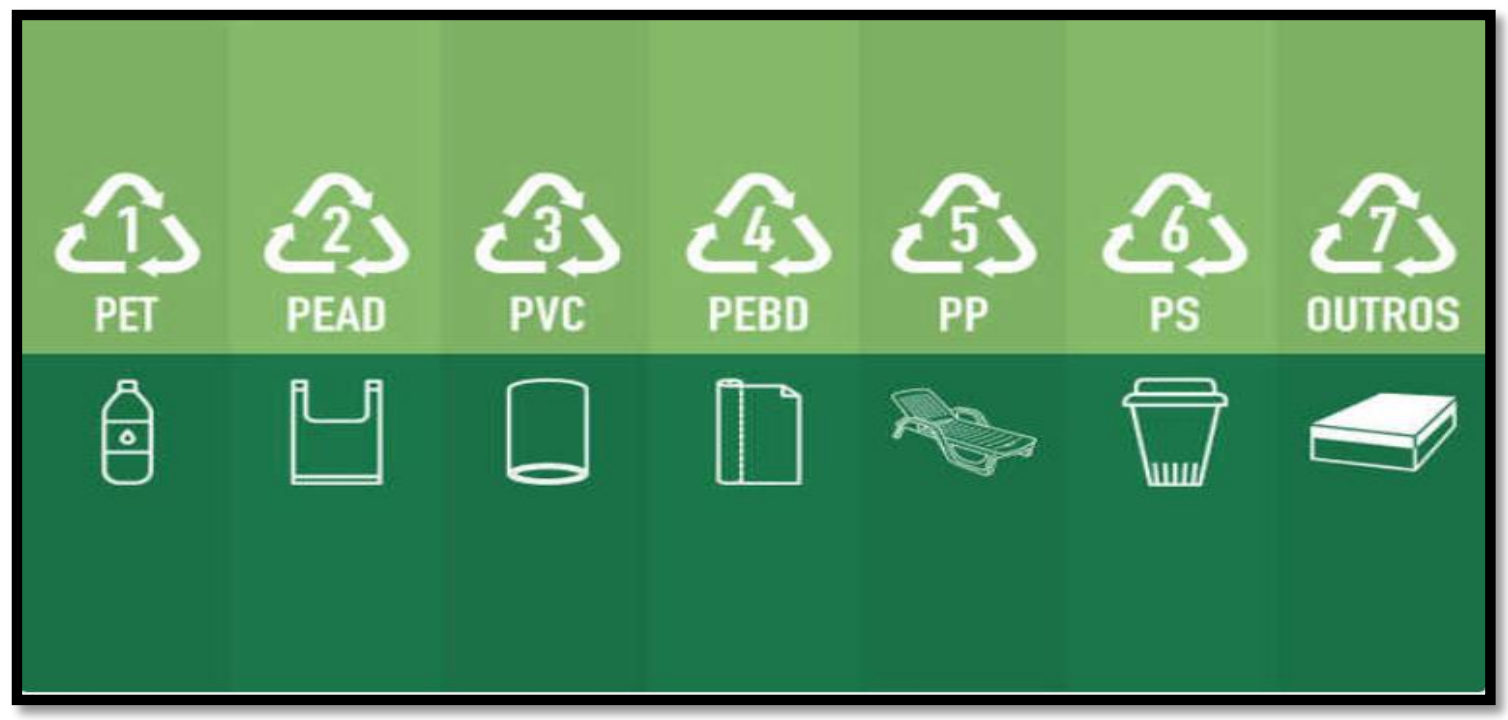

Fonte: ecycle

Segundo Romão (2009), o poli(tereftalato de etileno), mais popularmente conhecido como PET, é um dos termoplástico mais produzido no mundo, estíma-se que só 
na década de 1990, a quantidade desse material gerada chega a uma grandeza de 2,4 $\times$ $10^{10} \mathrm{Kg}$, sendo atraente o seu uso e consulmo devido as propriedade mecânicas, térmicas e o custo de produção baixo.

Romão (2009) ainda informa que no Brasil, a principal aplicação PET é na industria embalagem que na época correspondia a $71 \%$, sendo $32 \%$ destinado a indústria alimentícia. A indústria de reciclagem de polímeros no Brasil é constituída por cerca de 490 empresas recicladoras, $80 \%$ delas concentradas na região Sudeste com faturamento de R \$ I,22 bilhão/ano, gerando II.50o empregos diretos (Brognoli 2006).

Segundo o site da ecopipe, o polietileno é o polímero com a estrutura química mais simples da família dos termoplásticos, e por ser obtido através de uma polimerização do eteno, adquiri o nome de polietileno, sendo muito indicado na fabricação de tubos devida a suas excelentes propriedades mecânicas, físicas, químicas e hidráulica. Entretanto, o PEAD é também frequentemente encontrado em embalagens de óleos automotivos e sabões líquidos, sacolas de supermercados, tampas, tambores para tintas, entre outros.

De acordo com Nunes (2002), o cloreto de Polivinil, é entre os plásticos um dos mais consumidos do Planeta e é conhecido pela sigla PVC. Teve sua descoberta em I835, mas só obteve sua produção com valor comercial a partir de 1927. FERNANDES 2016, fala que o PVC é também conhecido como um polímero polivalente pois apresenta formas desde muito rígidas como muito flexíveis, na construção civil o policloreto de polivinila é constantemente utilizado na confecção de tubos, conexões, fios e cabos.

Segundo o site da Ecycle, o PEBD é um tipo de plástico muito utilizado por ser flexível, leve, transparente e impermeável e por se tratar de um termoplástico é reciclável, suas aplicações vão de sacolas para supermercado e boutiques, sacolas de soros medicinais, filmes utilizados para embalar ou mesmo que constituem fraudas descartáveis.

O PS é o pioneiro entre os termoplásticos, a primeira planta industrial a operar comercialmente com sucesso foi a IG Farbenindustrie, na Alemanha, em 1930, entretanto, nos Estados Unidos, o poliestireno foi produzido em escala comercial, pela primeira vez, em 1938, pela Dow Chemical Company (MONTENEGRO, 2002). No site da Ecycle é possível encontrar a forma em que é vastamente utilizado como por exemplo em potes para iogurtes, sorvetes, doces, frascos, bandejas de supermercados como podemos ver na figura 6, geladeiras (parte interna da porta), pratos, tampas, copos descartáveis. 


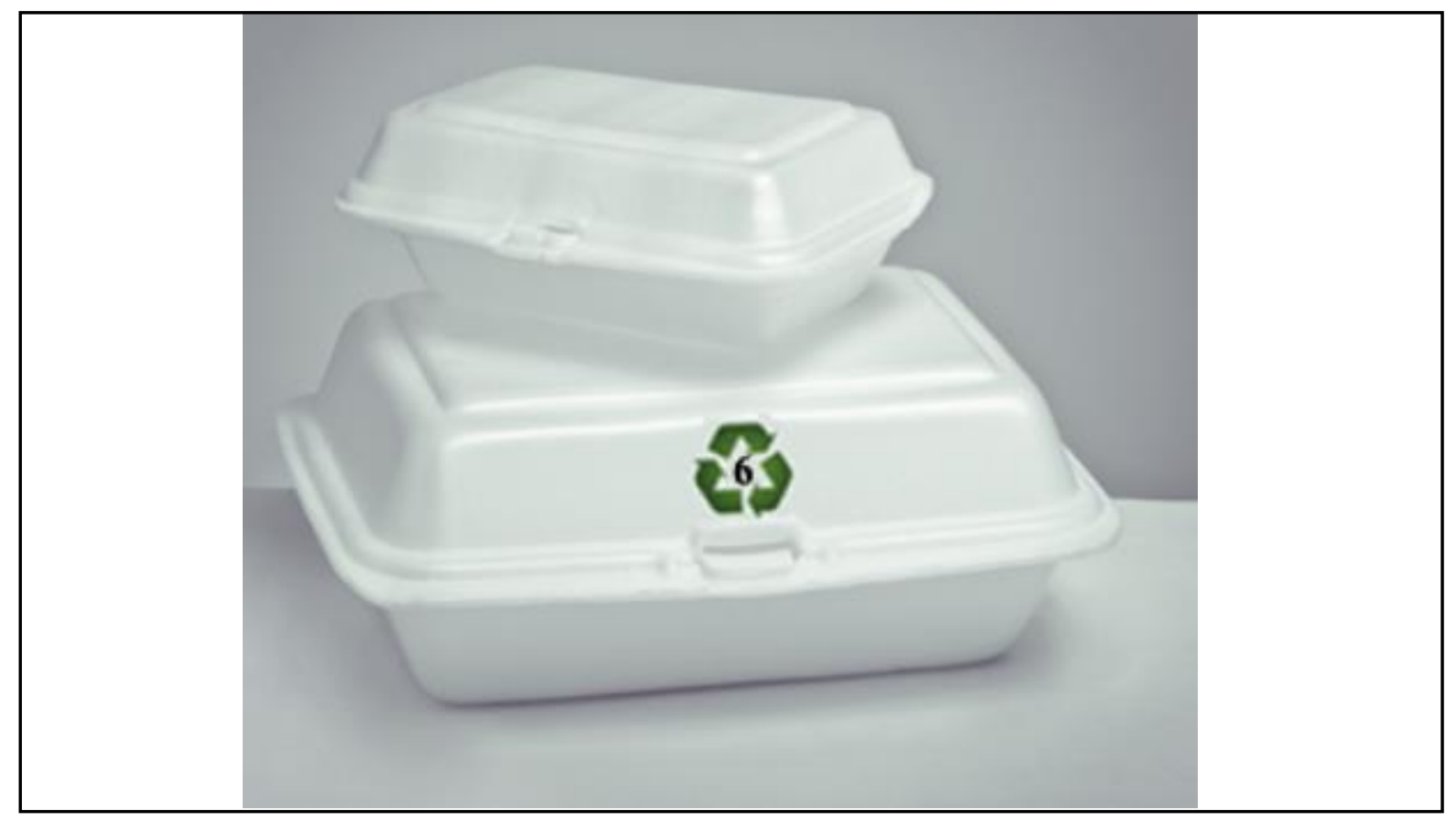

Figura 6 - Recipiente a base de PS

Fonte: Google imagens

\subsubsection{Polipropileno (PP)}

Segundo o artigo publicado na revista TECHNE com o título "Principais tipos de plásticos usados nos produtos e sistemas construtivos", desde a sua introdução em I954, o polipropileno (PP) se tornou uma das mais importantes resinas termoplásticas.

É o terceiro termoplástico mais vendido no mundo (abaixo do polietileno baixa densidade e do PVC), suas propriedades é de Alta rigidez, baixo peso específico (especialmente quando orientado), baixa condutividade térmica, sendo ele também facilmente moldado por injeção.

Suas limitações conhecidas são de pouca resistência ao impacto em baixas temperaturas e faixa reduzida da temperatura de fusão. As aplicações do polipropileno é na produção de fôrmas plásticas, telhas e distanciadores. As fibras de polipropileno podem ser adicionadas ao concreto e à argamassa para combater a fissuração por retração. 


\subsubsection{Polipropileno Isotático (iPP)}

SILVA 2017 fala que, este tipo específico de PP é um plástico muito importante na engenharia e é usado em diversas áreas (móveis, brinquedos e peças para indústria automóvel). O Homem, atualmente, faz uso diário de produtos em iPP e procura desenvolver novos produtos à base deste polímero e procura atender aos requisitos atuais de materiais com melhores propriedades ambientais, mecânicas, térmicas e óticas.

No quadro 2, está presente as propriedades do polipropileno isotático (ipp), sendo essa propriedade a densidade, Módulo de Young, Resistência à tração, condutividade elétrica, Condutividade térmica e ponto de fusão

Quadro 2 - Propriedades do PP

\begin{tabular}{|l|l|l|}
\hline Propriedade & Valores & Unidades \\
\hline Densidade & $900-909$ & $\mathrm{~kg} / \mathrm{m}^{3}$ \\
\hline Módulo de Young & $\mathrm{I}, 6-\mathrm{I}, 78$ & $\mathrm{GPa}$ \\
\hline Resistência à tração & $36,2-49$ & $\mathrm{MPa}$ \\
\hline Condutividade elétrica & $0,001689-0,015836$ & $\mathrm{~s} /(\mathrm{cm})$ \\
\hline Condutividade térmica & 0,25 & $\mathrm{~W} /(\mathrm{mK})$ \\
\hline Ponto de fusão & $\mathrm{I} 65$ & $\mathrm{o} \mathrm{C}$ \\
\hline
\end{tabular}

Fonte: Adaptado Silva, (2017)

\subsubsection{Reciclagem}

Compreender a forma utilizada para reciclar os termoplásticos é necessário para entender os processos que deverão ser tomados, Spinacé (2005) fala que existem 4 categorias para reciclar polímeros, e consequentemente, termoplásticos. Essas categorias são classificadas como primária, secundária, terciária e quaternária.

A primária consiste em processamentos padrões em fábricas ou indústrias, de forma que o material é misturado com produtos que possuem características similares, nesse caso, o material virgem. A secundária se trata da utilização de polímeros pósconsumo, como é o caso do PP reciclado para fabricação de sacos de lixo, ou seja, 
convertendo produtos de natureza polimérica derivados de resíduos sólidos urbanos combinando produtos obtidos pelo mesmo material virgem.

Já a reciclagem terciária, trata-se de um reaproveitamento utilizando materiais químicos, podendo ser conhecida também como "Reciclagem química", que geram insumos químicos ou até mesmo combustíveis através de resíduos poliméricos. A quaternária é um processo mais energético, que ainda segundo Spinacé (2005), é um processo tecnológico de recuperação de energia de resíduos poliméricos por incineração controlada.

\subsection{Engenharia e os materiais compósitos}

Carneiro (2008) fala que, na engenharia o aço foi amplamente utilizado na década de 6o, entretanto, devido aos problemas que ocasionavam como a corrosão e posteriormente a perca de aderência com o concreto, tinha-se também o seu elevado peso, preço e elevada manutenção nos empreendimentos desse tipo, portanto, na década de 9o, houve uma diminuição na sua demanda devido a necessidade de estruturas mais leves, e nessa mesma época estaria ali o aperfeiçoamento de materiais do tipo compósito.

Carneiro (2008), ainda conclui sua fala informando que, compósitos são materiais cuja estrutura é constituída por uma combinação de dois ou mais produtos não solúveis entre si, os compósitos do tipo poliméricos começaram a ser empregados em indústrias aeronáuticas, aeroespacial, militar, naval, automobilística e de materiais esportivos, e posteriormente, tornou-se cada vez mais atraente para a sua utilização na construção civil.

\subsection{1 polímeros}

É notório que os sistemas construtivos tem evoluído através dos séculos, os conhecimentos obtidos de novos materiais possibilitou a engenharia a vencer obstáculos antes tomados como impossíveis. Segundo Mano (1991) o primeiro material de engenharia utilizado pelo Homem foi a madeira, e por último os polímeros, como podemos observar no Quadro 3.

O marco histórico do polímeros, deve-se a confirmação de que, materiais 
produzido através da química incipiente que antes considerado colóides (misturas em que as partículas dispersas têm um diâmetro compreendido entre I nanômetro e I micrometro, partículas estas que podem ser átomos, íons ou moléculas), era formado na verdade por uma espécie de moléculas gigantes, resultando em uma cadeia de ı.ooo ou mais átomos de carbono.

Essa repetições de pequenas unidades ao longo de toda cadeia principal foi denominada de polímeros (do grego, "muitas partes"). Outros materiais encontrados na natureza também possuí a características de possuir imensas moléculas, como é o caso da madeira, lã, borracha, DNA entre outros (Mano, 199ı).

Quadro 3 - Evolução dos materiais de engenharia

\begin{tabular}{|c|c|c|c|}
\hline \multicolumn{2}{|c|}{ Evolução histórica } & \multirow{2}{*}{$\begin{array}{l}\text { Ano } \\
25.000 \quad \text { AC até } \\
6.500 \mathrm{AC}\end{array}$} & \multirow{2}{*}{$\begin{array}{l}\text { Material } \\
\text { Madeira } \\
\text { Pedra lascada } \\
\text { Pedra polida }\end{array}$} \\
\hline Pré-história & Idade da pedra & & \\
\hline Proto-história & Idade dos metais & $\begin{array}{l}6500 \text { AC até } 1500 \\
\text { AC }\end{array}$ & $\begin{array}{l}\text { Cobre } \\
\text { Estanho } \\
\text { Bronze } \\
\text { Ferro } \\
\text { Cerâmica }\end{array}$ \\
\hline \multirow[t]{4}{*}{ História } & Idade antiga & $\begin{array}{l}4000 \mathrm{AC} \text { até } \\
500 \mathrm{AC}\end{array}$ & Vidro \\
\hline & Idade média & 500 até 1500 & Ligas metálicas \\
\hline & Idade moderna & I500 até 1800 & Concreto \\
\hline & Idade contemporânea & $\begin{array}{l}\text { I8oo até os dias } \\
\text { atuais }\end{array}$ & Polímeros \\
\hline
\end{tabular}

Fonte: Adaptado Mano I991

\subsubsection{Compósitos poliméricos}

Os compósitos vão possuir 2 ou mais partes, uma como matriz e a outra parte como fase de reforço, Carneiro (2008), fala ainda que a parte matricial envolve a parte do 
reforço formando um novo material, ou seja, na fase de fabricação de uma compósito, é utilizado um material "A" como matriz e determinado "B" como reforço, criasse então um material não " $\mathrm{AB}$ " e sim um material "C", novo, com propriedades diferentes dos que o originaram.

Neste caso, os materiais compósitos poliméricos, trata-se de um compósito que possuirá em sua matriz um material polimérico e um reforço para criação de um novo material, sendo muitas vezes esse reforço, uma fibra. A escolha da resina mais adequada depende do tipo de ambiente o qual o compósito estará submetido. As fibras, por outro lado, devem ser selecionadas em função da resistência, rigidez e durabilidade requeridas (Carneiro 2008).

\section{METODOLOGIA \\ 3.I Materiais e métodos}

Essa pesquisa foi desenvolvida com base na pesquisa bibliográfica que conforme Salomon (2004), fundamenta-se em conhecimentos proporcionados pela Biblioteconomia e Documentação entre outras ciências e técnicas empregadas de forma metódica envolvendo a identificação, localização e obtenção da informação, fichamento e redação do trabalho científico (BOCCATO, 2006).

O presente trabalho foi sustentado por pesquisas em artigos científicos, monografias, periódicos e livros publicados advindas de arquivos nacionais e internacionais (espanhol/Inglês/Português).

\subsection{Procedimentos analíticos}

Dessa forma, o material exposto buscou agrupar o conteúdo já existente afim de levantar um novo questionamento relacionado à inferência do grafeno em materiais à base de polipropileno. Esta monografia é composta por materiais bibliográficos com a intenção de apresentar o grafeno de forma geral tal como sua: composição, formas de obtenção, meios de utilização e valor aquisitivo do produto. Sendo também pertinente e necessário a inferência sobre materiais compósitos, poliméricos (sendo esse destacado os termoplásticos com uma ênfase no polipropileno).

Entretanto, este trabalho não buscou aprofundar-se sobre a parte química que envolve os compósitos, grafenos e seus derivados referente a sua obtenção e 
comportamento, sendo também irrelevante para a conclusão dos objetivos a forma em que o material de reforço se instala na matriz polimérica, os métodos de reciclagem dos termoplásticos e as normas que envolve o quadro 5 e 6.

\section{DISCUSSÃO}

Segundo OLIVEIRA (2017), O Brasil ainda não é referência na fabricação e desenvolvimento de pesquisas na área do grafeno, entretando está previsto um investimento em escala piloto do projeto Mggrafeno - produção de grafeno apartir da Esfoliação Química de Grafite natural e aplicação - cujo o valor do investimento é de aproximadamente 21,3 milhões de reais ao decorrer de 3 anos. Esse centro será responsável pelas pesquisas na área do grafeno, assim como o desenvolvimento tecnológico do grafeno e a produção por esfoliação química.

O retorno financeiro para o país que desenvolver em escala industrial o grafeno, será bastante expressívo, devido ao baixo valor do grafite (materia prima para produção do grafeno). OLIVEIRA (2017) afirma que, atualmente, ikg de grafite equivale a US $\$ 1$, enquanto que ig de grafeno é o equivalente a US\$Ioo. Espera-se também que com o investimento na tecnologia, nova empresas de alta tecnologia que possam utilizar da matéria prima, migrem para o Brasil. Consequentemente, isso irá aumentar as vagas de emprego e oportunidades para investidores.

No Brasil, Kuiava (2020), reitor da UCS, explica que o valor do grefeno varia de acordo com a sua utilidade e uso ao material ao que vai ser aplicado, entretanto afirmase que a média chega a um valor de $\mathrm{R} \$ 5$ mil para cada quilo produzido. O valor da receita gerada com base na fabricação atual da UCS (50oKg/ano) é de $\mathrm{R} \$ 2,5$ milhões de reais por ano, podendo depois avançar para aproximadamente $\mathrm{R} \$ 25$ milhões de reais, devido ao projeto de ampliação que visa um aumento da fabricação para 5 toneladas por ano

Já, a respeito da utilização do grafeno em compósitos, Segundo BORSCHIVER (2005), A Nanotecnologia tem causado um grande avanço área de desenvolvimento tecnológico devido a variedades de formas de aplicação. Uma dessas variedades, se encontra no reforço de matrizes poliméricas e a criação de novos compósitos 
Devido à disposição dos átomos na estrutura de grafeno, as características mecânicas atingem valores muito elevados, podendo alcançar dezenas de vezes os valores apresentados pelo aço carbono. Exemplos de propriedades mecânicas do grafeno são altos valores de módulo de Young (1,5 TPa) e resistência à tração $130 \mathrm{GPa}$ (CORSO et al, 2019).

A partir disso, sua utilização em vários tipos de compósitos como carga de reforço é viável devido à combinação dessas propriedades mecânicas, as características nanoestruturadas, sua baixa densidade e sua alta flexibilidade (EDA et al., 2008; LEE et al., 2008).

Como é o caso do concreto de grafeno cujo um grupo da Universidade de Exerter, na Grã-Bretanha (Figura 7), desenvolveu uma forma de elevar os flocos de grafeno na água e misturar com o cimento e agregados, segundo o site Plantas de casa, através desse novo compósito reforçado, pode se obter um aumento $146 \%$ na resistência à compressão em comparação com o concreto comum, um aumento de 79,5\% na resistência à flexão e uma diminuição na permeabilidade à água de quase 400\%.

Figura 7 - Blocos de concreto de grafeno

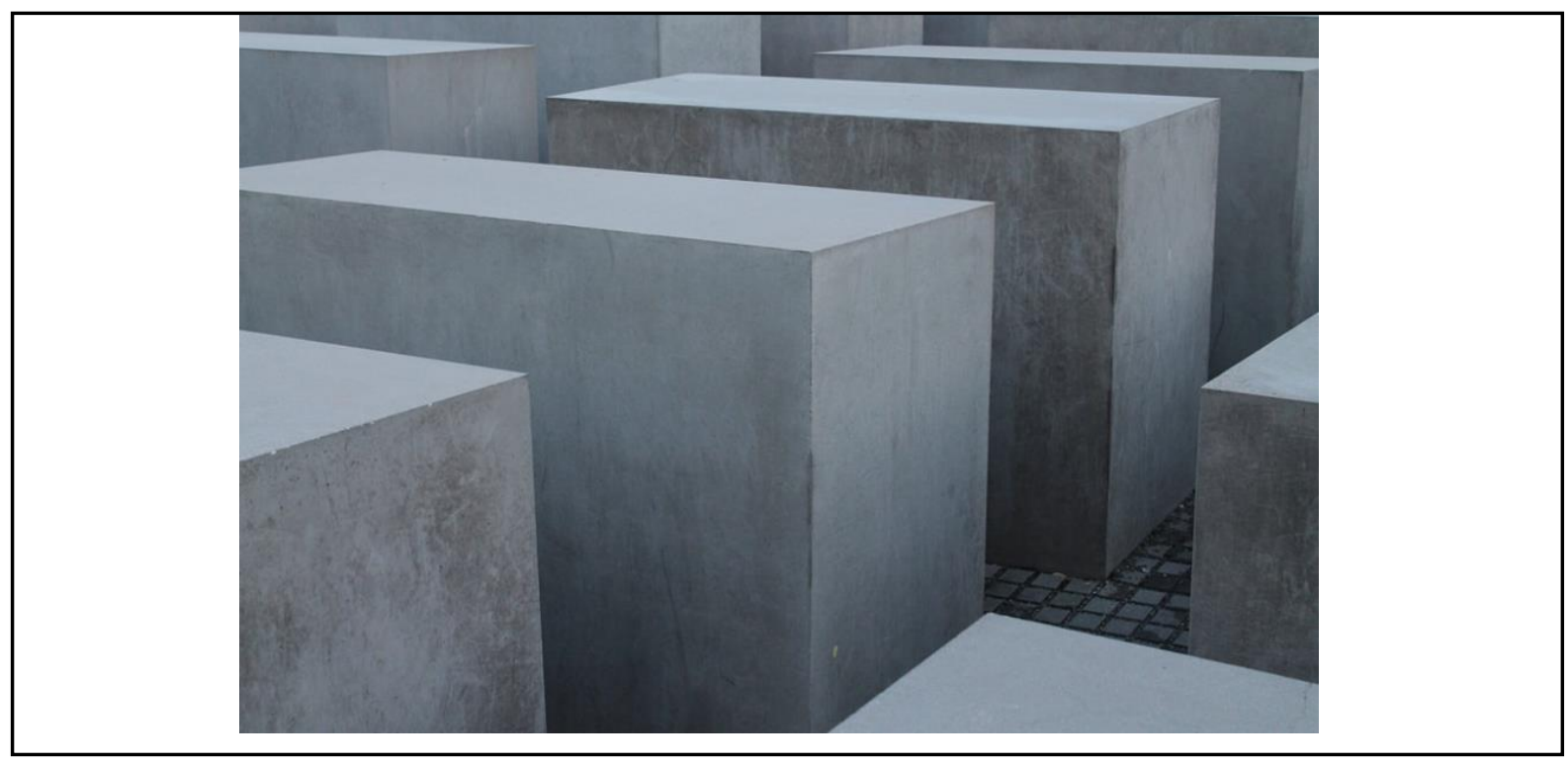

Fonte: plantasdecasas

Segundo CORSO et al, foi possível sintetizar e caracterizar óxidos de grafeno com diferentes graus de oxidação. Os materiais compósitos apresentaram resultados satisfatórios para o ensaio de tração. Os valores obtidos para os ensaios de módulo de elasticidade e tensão de tração foram superiores aos dos corpos de prova com polipropileno 
puro, confirmando mais uma vez uma oxidação efetiva. O óxido de grafeno obtido é viável para incorporação em matriz polimérica de polipropileno, pois apresentou boas propriedades mecânicas, sendo economicamente viável.

Segundo Hernández et al (2014), Devido às excelentes propriedades do grafeno, um importante objeto de estudo no momento é encontrar uma maneira de aproveitar essas propriedades ao máximo para o reforço de matrizes poliméricas. Os principais desafios para esta aplicação são; a produção de folhas de grafeno em quantidades necessárias para a fabricação de compósitos poliméricos e a dispersão adequada das referidas folhas nas matrizes poliméricas. Hernández ainda conclui que Adição de óxido de polietileno como compatibilizante de compósitos Polipropileno/Grafeno, promove aumento no módulo de elasticidade, de acordo com os resultados dos testes de Análise Mecânica Dinâmico.

Já Carlos A. Guerrero Salazar et al (2019) fala que a viscosidade dinâmica do PET reforçado com rGO é muito maior que a do PET virgem, especialmente em altas frequências; quanto maior o teor de reforço, maior a viscosidade.

Em baixas concentrações de Óxido de grafeno reduzido (rGO), o módulo elástico do material reforçado não é afetado; no entanto, para amostras com 5\% de rGO, o módulo de elasticidade aumenta em altas temperaturas, passando de $5 \mathrm{MPa}$ para material virgem a $40 \mathrm{MPa}$ para compósito, além disso, uma das amostras em que foi utilizada 26,46 gramas de PET com adição de $0,5 \% \mathrm{rGO}$ e $5 \%$ ionômero de poliéster (PETi), que é uma espécie de agente de acoplamento que auxiliará na fundição, obtendo assim um material compósito de nível elevado em módulo elástico que chega a $90 \mathrm{MPA}$, como podemos acompanhar no Quadro 4.

Dessa forma, obtém-se um material que possui uma resistência equivalente em módulo elástico(E') aproximadamente a $0,04 \%$ do que o aço que possui um E' de 207 GPA (Carlos A. Guerrero Salazar et al, 2019)

Quadro 4 - Alteração nas propriedades elásticas com adição do grafeno

\begin{tabular}{|c|c|}
\hline SUBSTÂNCIA UTILIZADA & ALTERAÇÃO DO MÓDULO \\
& ELÁSTICO \\
\hline Baixa concentração de rGO & Sem alteração \\
\hline $5 \%$ de rGO & De 5 MPA para 40 MPA \\
\hline
\end{tabular}


Fonte: Adaptado Salazar, 2019

SILVA (2017), fala que ao fazer testes que visava analisar a influência do teor de grafeno nas propriedades mecânicas do polipropileno isotático, de modo a otimizar as condições de mistura e processamento dos nanocompósitos, obtém-se a partir de ensaios que as conclusões preliminares que podem ser inferidas dizem respeito à viscosidade aparente que parece diminuir até a um valor mínimo função do teor de grafeno multicamadas (MLG).

Além disso, foi também obtido apartir dos ensaios que a adição de MLG não contribuiu de forma positiva para o módulo de elasticidade, que com a adição de apenas o,5\% $(\mathrm{m} / \mathrm{m})$ de MLG teve um decréscimo de 54\%, ou seja, para essas condições é válido a utilização do MLG em iPP (polipropileno isotático) quando o mesmo possuir uma fluidez muito elevada e deseja-se fazer uma correção (SILVA, 2017).

Referente aos testes de tração valores são ligeiramente mais baixos, contrariamente ao que se esperava devido ao melhoramento das condições da injeção, e por fim, (SILVA 2017) salienta que o comportamento do iPP com a adição de MLG não proporcionou melhoramento no desempenho mecânico como seria expectável.

Entretanto, outra forma de avaliar a eficiência do grafeno em materiais polipropileno, é fazendo uma breve comparação com a matriz polimérica a base de PP acrescentado de um reforço matricial de Fibra de vidro (FV). OTA (2004) diz que, De acordo com fabricante, o polipropileno utilizado componentes automotivos é não-tóxico, quimicamente inerte e é insolúvel em solventes comuns. Sendo as propriedades fornecidas pelo fabricante, contida no quadro 5 .

Dessa forma, percebe-se que, no quadro 5 e no quadro 6 as propriedades em comum, como o Índice de Fluidez, Densidade, módulo de flexão, resistência à tração no escoamento, Temperatura de deflexão térmica - $\operatorname{HDT}(\mathrm{I}, 82 \mathrm{MPa})$ e Temperatura de deflexão térmica - $\operatorname{HDT}(o, 45 \mathrm{MPa})$, houve divergências quando o polímero recebe um reforço matricial da FV, essa comparação pode ser observada no gráfico I.

O gráfico I, possui elementos a respeito das alterações obtidas em cada tipo de $\mathrm{PP}$ (PP puro, $\mathrm{PP}_{20} \% \mathrm{FV}$ e $\mathrm{PP}_{30 \% \mathrm{FV}}$ ), onde se pode notar um decréscimo na fluidez do polímero e um aumento nas demais propriedades analisadas. 
Continuamente, pode-se comparar com a quadro 6, onde encontra-se as propriedades do compósito $\mathrm{PP}+\mathrm{FV}$, a tabela vai trazer na sua coluna 4 e 5 a matriz, a porcentagem e o reforço, sequencialmente.

Quadro 5 - Propriedade do PP utilizado em automotivos

\begin{tabular}{|c|c|c|c|}
\hline PROPRIEDADES & NORMA & UNIDADE & VALOR \\
\hline Índice de Fluidez $\left(230^{\circ} \mathrm{C} / 2,16 \mathrm{~kg}\right)$ & ISO II33 & $\mathrm{g} / \mathrm{Io} \min$ & 7,5 \\
\hline Densidade & ISO II83 & $\mathrm{g} / \mathrm{cm}^{3}$ & $0,9 \mathrm{I}$ \\
\hline Ponto de fusão & $\mathrm{ISO}_{3146}$ & ${ }^{\circ} \mathrm{C}$ & $160-165$ \\
\hline Módulo de flexão & ISO I78 & MPA & 1300 \\
\hline Resistência à tração no escoamento & ISO 527-2 & MPA & 34 \\
\hline Impacto IZOD sem entalhe a $23^{\circ} \mathrm{C}$ & ISO I $80-4 / \mathrm{A}$ & $\mathrm{J} / \mathrm{m}$ & 25 \\
\hline $\begin{array}{c}\text { Temperatura de deflexão térmica - } \\
\operatorname{HDT}(\mathrm{I}, 82 \mathrm{MPa})\end{array}$ & $\mathrm{ISO} 75^{-2} / \mathrm{A}$ & $\stackrel{\mathrm{o}}{\mathrm{C}}$ & 57 \\
\hline $\begin{array}{c}\text { Temperatura de deflexão térmica - } \\
\operatorname{HDT}(0,45 \mathrm{MPa})\end{array}$ & ISO $75^{-2} / \mathrm{B}$ & $\stackrel{\mathrm{o}}{\mathrm{C}}$ & 105 \\
\hline Vicat $(\mathrm{Ikg})$ & ISO 306 & o $\mathrm{C}$ & 152 \\
\hline
\end{tabular}

Fonte: Adaptado OTA (2004)

Quadro 6 - Propriedades do Polipropileno modificado com a adição de fibra de vidro.

\begin{tabular}{|c|c|c|c|c|}
\hline PROPRIEDADES & NORMA & UNIDADE & $\mathrm{PP}_{20 \% \mathrm{FV}}$ & $\mathrm{PP}_{30 \% \mathrm{FV}}$ \\
\hline $\begin{array}{c}\text { Índicie de Fluidez }\left(230^{\circ} \mathrm{C} / 2,16\right. \\
\mathrm{kg})\end{array}$ & ISO II33 & $\mathrm{g} /$ Io $\mathrm{min}$ & 5,0 & 2,9 \\
\hline Teor de carga & ISO $345^{1-I}$ & $\%$ & 20,0 & 30,0 \\
\hline Densidade & ISO 1183 & $\mathrm{~g} / \mathrm{cm}^{3}$ & $\mathrm{I}, 05$ & $\mathrm{I}, 33$ \\
\hline Módulo de flexão & $\mathrm{ISO}_{\mathrm{I} 78}$ & MPA & 3900 & 5800 \\
\hline $\begin{array}{c}\text { Resistência à tração no } \\
\text { escoamento }\end{array}$ & ISO $527-2$ & MPA & 70 & 80 \\
\hline $\begin{array}{c}\text { Impacto CHARPY sem entalhe } \\
\text { a } 23^{\circ} \mathrm{C}\end{array}$ & $\begin{array}{c}\text { ISO } \\
\mathrm{I} 79 / \mathrm{reU}\end{array}$ & $\mathrm{kJ} / \mathrm{m}^{2}$ & 26 & 27 \\
\hline $\begin{array}{l}\text { Temperatura de deflexão } \\
\text { térmica - HDT }(\mathrm{I}, 82 \mathrm{MPa})\end{array}$ & $\begin{array}{l}\text { ISO } 75^{-} \\
2 / \mathrm{A}\end{array}$ & $\stackrel{\circ}{-} \mathrm{C}$ & 130 & 145 \\
\hline $\begin{array}{l}\text { Temperatura de deflexão } \\
\text { térmica - HDT (o,45 MPa) }\end{array}$ & $\begin{array}{l}\text { ISO } 75^{-} \\
2 / \mathrm{B}\end{array}$ & $\stackrel{\circ}{ } \mathrm{C}$ & 145 & 155 \\
\hline Vicat $(5 \mathrm{~kg})$ & $\begin{array}{l}\text { ISO 306- } \\
\mathrm{VS} / \mathrm{B} / 50\end{array}$ & $\stackrel{\circ}{ } \mathrm{C}$ & 152 & 130 \\
\hline $\begin{array}{c}\text { Resistência Termo-Oxidação a } \\
150^{\circ} \mathrm{C}\end{array}$ & ISO 4577 & Horas & 1000 & 1000 \\
\hline
\end{tabular}

Fonte: Adaptado OTA (2004) 
Gráfico $\mathrm{I}$ - Comparativo das propriedades modificadas entre o $\mathrm{PP}, \mathrm{PP}_{20} \% \mathrm{FV}, \mathrm{PP}_{30} \% \mathrm{FV}$

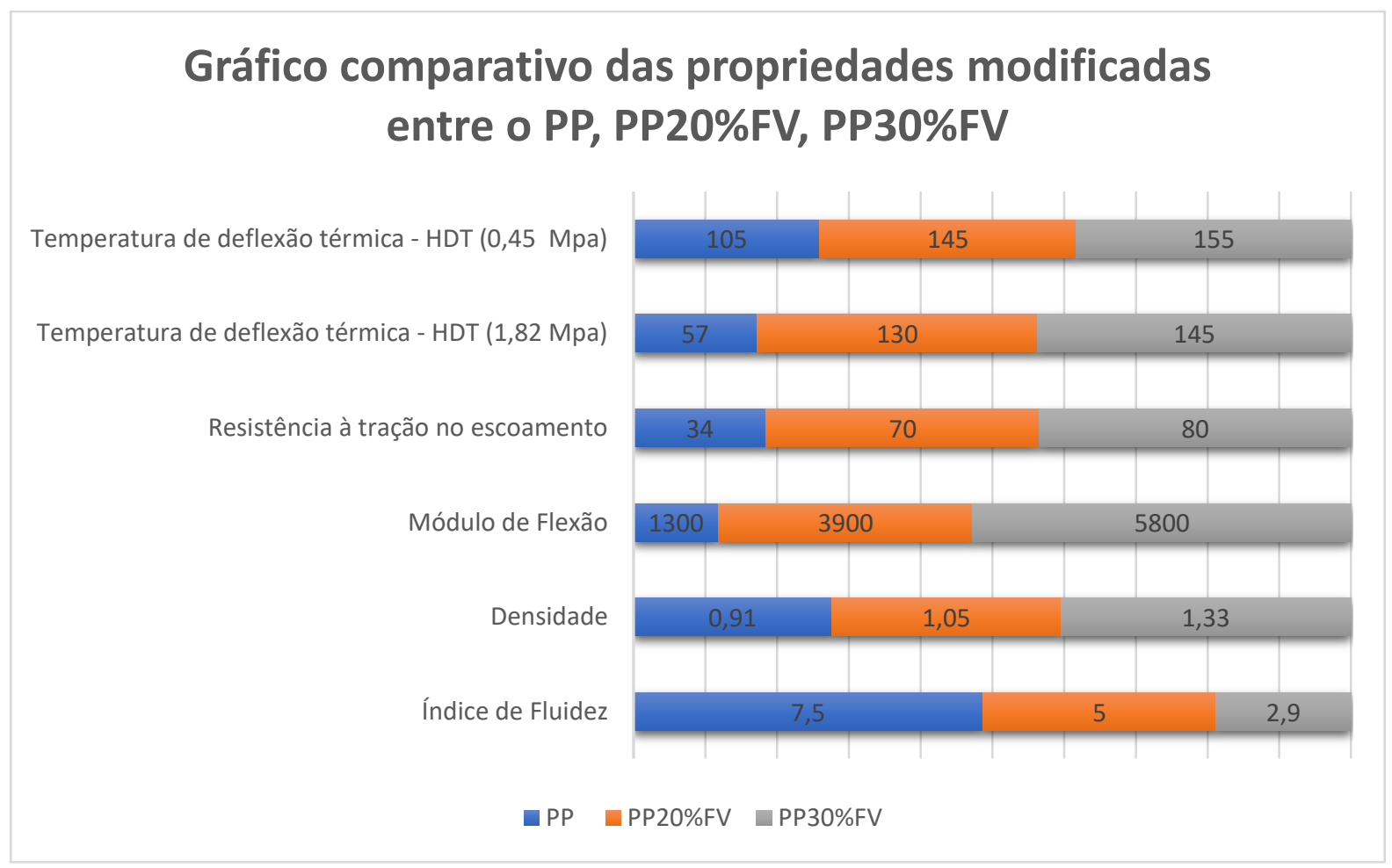

Fonte: Adaptado OTA (2004)

Outro fator importante e que se deve atentar, é a temperatura a qual ocorre a fusão dos materiais, pois ela pode influenciar na resistência e módulo elástico, podendo ser consultado na tabela I.

$\mathrm{Na}$ tabela I, é possível identificar as modificações do módulo elástico e a resistência a tração do PPo\%FV para o PP com 20\% e 30\% de Fibra de vidro. No gráfico 2, é possível identificar o maior valor para resistência a tração na amostra de $\mathrm{PP}_{30 \% \mathrm{FV}}$ quando a fusão ocorre a uma temperatura de $210^{\circ} \mathrm{C}$, entretanto, no gráfico 3 que tem como finalidade apresentar o módulo de elasticidade, o maior valor é obtido quando a fusão ocorre a $170^{\circ} \mathrm{C}$ em uma amostra de PP com $30 \%$ de Fibra de vidro.

Tabela I - Alteração das propriedades a diferentes temperaturas em ํㅡ.

\begin{tabular}{c|c|c|c|c}
\hline \multirow{2}{*}{ Material } & $\begin{array}{c}\text { Temperatura de } \\
\text { Injeção (oC) }\end{array}$ & $\begin{array}{c}\text { Resistencia à } \\
\text { Tração }(\mathrm{MPa})\end{array}$ & $\begin{array}{c}\text { Módulo Elástico } \\
(\mathrm{MPa})\end{array}$ & (\%) \\
\hline \multirow{2}{*}{ PPo\%FV } & 170 & 40,3 & 2500 & \multirow{2}{*}{$200-500$} \\
\cline { 2 - 4 } & 190 & 39,6 & 2605 & \\
\hline
\end{tabular}




\begin{tabular}{|c|c|c|c|c|}
\hline & 210 & 37,8 & 2366 & \\
\hline & 230 & 38,2 & 2463 & \\
\hline & 250 & 37,8 & 2398 & \\
\hline \multirow{5}{*}{$\mathrm{PP}_{20 \% \mathrm{FV}}$} & 170 & $7 \mathrm{I}, 9$ & 6905 & 2,4 \\
\hline & 190 & 69,8 & 5832 & 2,5 \\
\hline & 210 & 69,3 & 6528 & 2,6 \\
\hline & 230 & 71,6 & 5953 & 2,5 \\
\hline & 250 & 72,5 & 5561 & 2,5 \\
\hline \multirow{5}{*}{$\mathrm{PP}_{30 \%} \mathrm{FV}$} & 170 & $8 \mathrm{I}, 9$ & 10183 & $\mathrm{I}, 7$ \\
\hline & 190 & 86,3 & 9397 & I,9 \\
\hline & 210 & 87,5 & 9279 & I,9 \\
\hline & 230 & $85, \mathrm{I}$ & 9025 & 2,0 \\
\hline & 250 & 86,6 & 8262 & 2,2 \\
\hline
\end{tabular}

Fonte: Adaptado OTA 2004

Gráfico 2 - Resistencia a tração do PP com a variação de temperatura

Gráfico da alteração da Resistência a Tração do PP em diferentes temperaturas

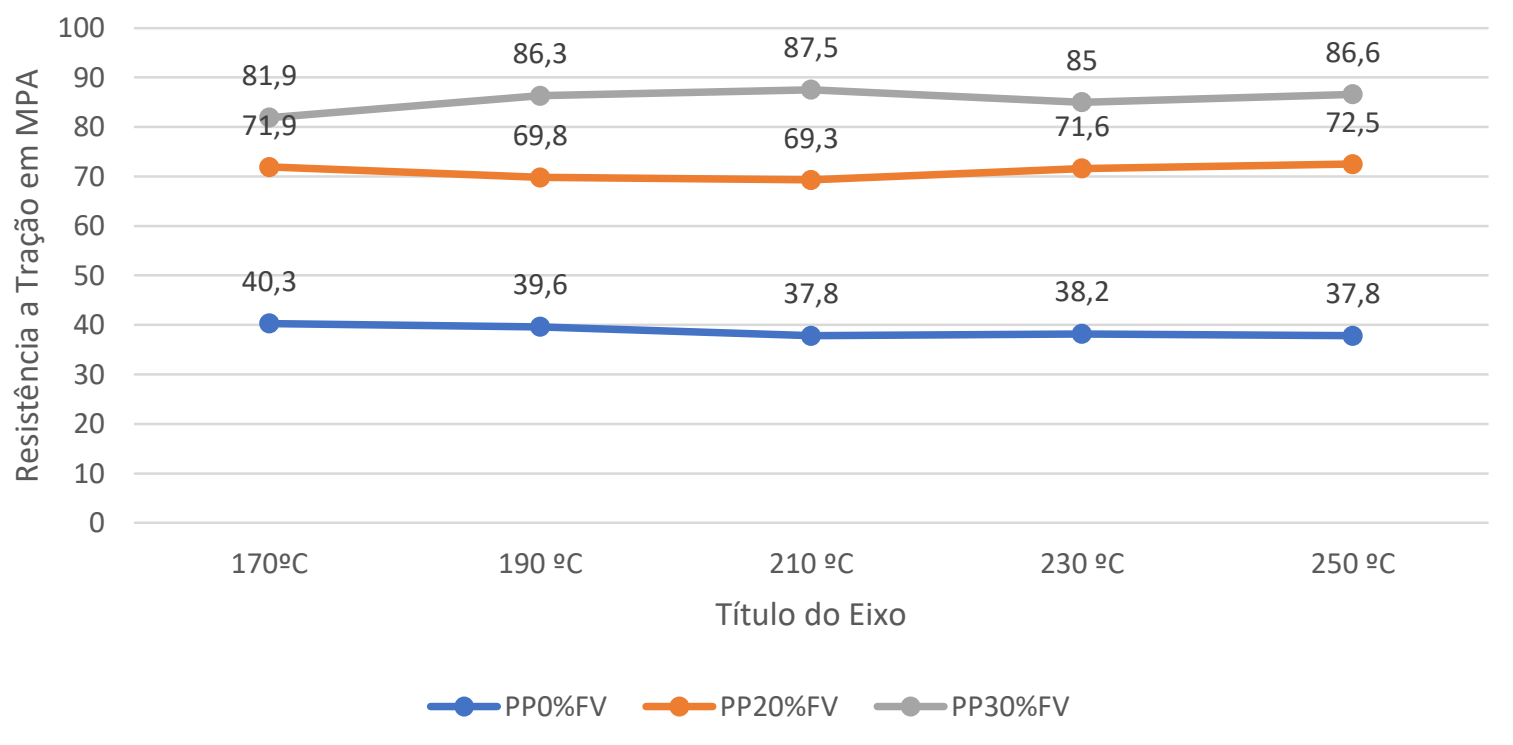

Fonte: Adaptado OTA, (2004) 


\section{Gráfico da alteração do Módulo de Elasticidade do PP em diferentes temperaturas}

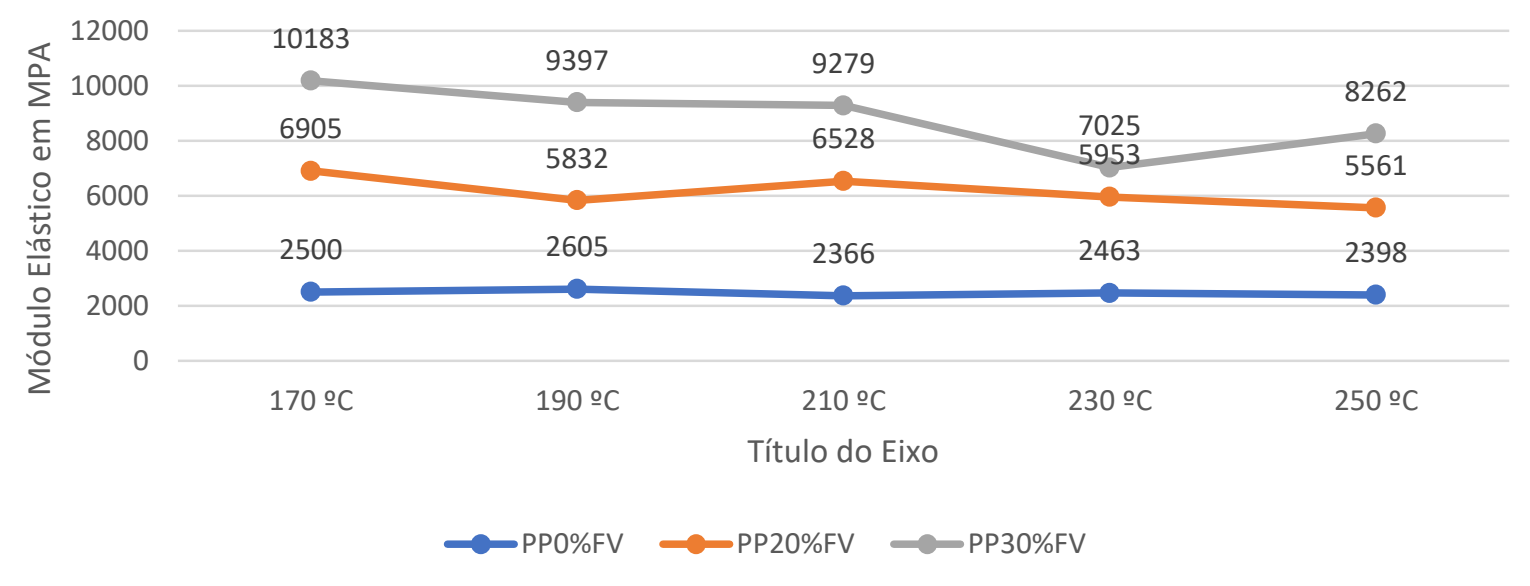

Gráfico 3 - Módulo Elástico do PP com a variação de temperatura

Fonte: Adaptado OTA, (2004)

Portanto, na premissa do que foi apresentado por BORSCHIVER (2005), existe um avanço na área nano-tecnológica que tem influenciado diretamente nos materiais compósitos, sendo essa afirmativa sustentada na publicação do site plantasdecasa.com.br, onde traz a conhecimento que o processo de adição de derivados do grafeno pôde-se obter um concreto, ou seja, um compósito que aumentou significativamente suas propriedades mecânicas.

Entretanto, mesmo com as atuais propriedades do grafeno em que CORSO et al (2019) traz, a respeito do módulo de Young (I,5 TPa) e resistência à tração I3o GPa, é válido acrescentar que essas características até então não foi transmitida para os compósitos estudados por Carlos A. Guerrero Salazar et al, (2019) e Silva (2017). Por conseguinte, é possível identificar que nessas mesmas amostras com a exceção da utilização do grafeno no iPP que segundo Silva (2017) não proporcionou melhoramento no desempenho como seria expectável, que houve sim, uma melhora nos compósitos com reforço derivados do grafeno.

Deste modo, poder-se-á utilizar o grafeno como um reforço polimérico, entretanto, o compósito gerado ainda não possui um módulo elástico (ou módulo de Young) e resistência ao cisalhamento, alto o suficiente para a substituição do aço na 
construção civil, visto que segundo Carlos A. Guerrero Salazar et al (2019) com o experimento de $\mathrm{rGO}$ em um termoplástico, mais especificamente o poli(tereftalato de etileno), popularmente conhecido como PET, só obteve o,04\% do módulo de elasticidade do aço. Entretanto não houve uma comparação do módulo de elasticidade com o composto PP + Derivados do grafeno, para que pudesse haver uma comparação com o aço.

Visto que, o compósito gerado pelo concreto/grafeno, possuí um aperfeiçoamento significativo, acredita-se que é possível sim a criação de um compósito $\mathrm{PP} / \mathrm{Grafeno}$ que poder-se-á utilizar-se na construção civil como um protagonista do empreendimento, como por exemplo o projeto de ciclovias e estradas feitas com plásticos recicláveis, apresentado na figura 8 e na figura 9, apresentado por Ricardo Caruso, autor do artigo publicado em 2015 na web site da band UOL.

Este projeto, segundo o autor Ricardo Caruso, partiu da empresa holandesa VolkerWessels, segundo dados apresentado, a estrada seria capaz de suportar temperaturas próximas -40 a $80^{\circ} \mathrm{C}$, utilizando materiais plásticos que poluiriam por centenas de ano a natureza e diminuindo a emissão de $\mathrm{CO}_{2}$ para atmosfera, já que estipula-se que a construção de pavimentações convencionais geram 1,45 milhões de toneladas de dióxido de carbono. Com base nas pesquisas e conhecimentos atuais sobre o grafeno, existe a possibilidade de melhorar esse termoplástico reciclado, e provavelmente a sua utilização partiria inicialmente em ciclovias, avançando para vias locais e coletoras e posteriormente em vias de trânsito rápido.

Figura 8: Ciclovias com plásticos recicláveis

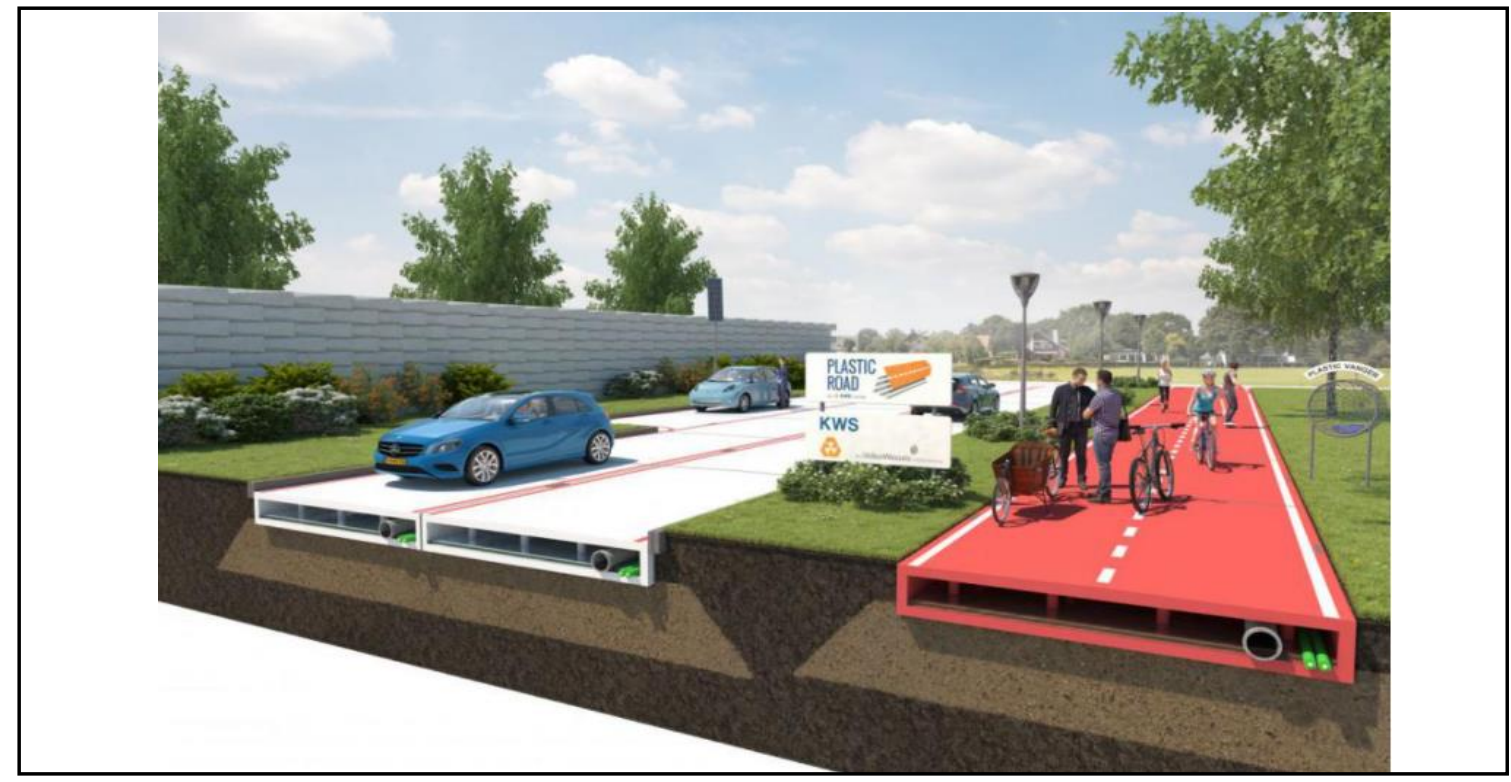


Fonte: autoetecnica.band.uol

Figura 9: Estradas com plásticos recicláveis

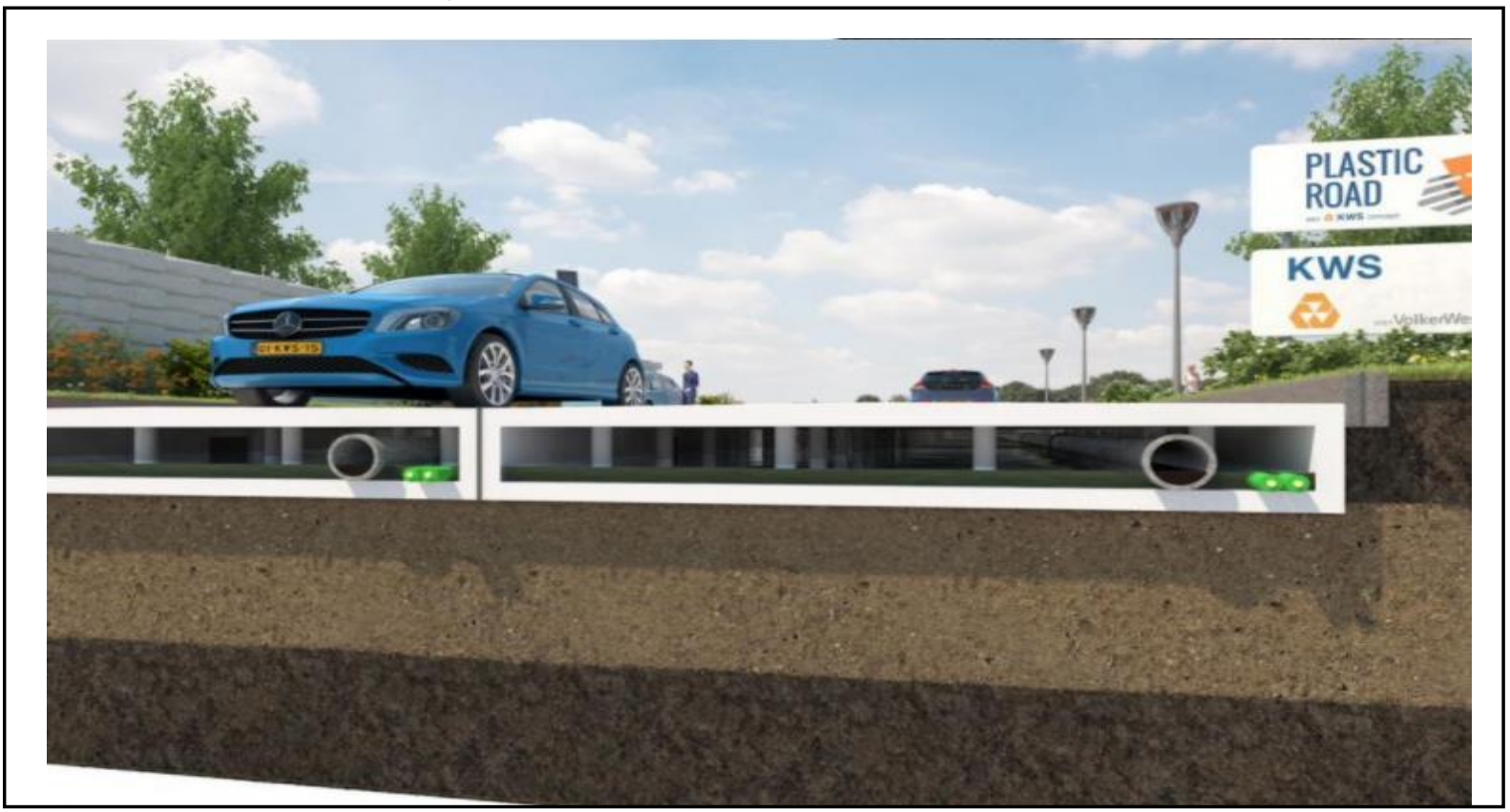

Fonte: autoetecnica.band.uol

CONSIDERAÇÕES FINAIS

Este trabalho consiste em derivar conclusões a partir de asserções conhecidas ou decididamente verdadeiras a respeito do grafeno e da sua viabilidade no uso em materiais compósitos dada uma ênfase para os do tipo polipropileno, podendo observar as mudanças na característica desses materiais, tais como as suas propriedades mecânicas e elástica, levantando-se através de conclusões, possibilidades para o uso de um polipropileno modificado na construção civil. Possivelmente, a melhoria de materiais do tipo PP, passará a fornecer equipamentos de segurança mais resistentes e consequentemente mais seguros.

Preliminarmente foi apresentado as justificativas para a pesquisa, entretanto, por se tratar de um material novo no aspecto de isolamento e métodos de obtenção, é escasso a quantidade de materiais bibliográficos visto a quantidade de possibilidades que é estudada sobre o grafeno, além do mais, reforça-se também a dificuldade de encontrar pesquisas científicas ou artigos de autores brasileiros. De forma geral, é existente a possibilidade de abrir caminhos para o aprofundamento de novas pesquisas na área dos 
compósitos e obter uma visão sustentável e ao mesmo tempo monetariamente benéfica para empresas.

Roberto Shinyashiki, autor, médico e psiquiatra brasileiro cita que "Um ser humano sem dúvidas não evolui. O questionamento é o primeiro passo para nos abrirmos para o novo". É, através dessa afirmação, que se pode previamente concluir que o levantamento das possibilidades do uso do grafeno é o primeiro passo para uma pesquisa aplicada na determinada área.

Como não é possível esgotar todo o tema, sugere-se aos interessados em continuar com a pesquisas: (I) Avaliar a viabilidade do uso do grafeno em Equipamentos de Proteção Individual (EPI), tal como a sua resistência e valor aquisitivo. (2) Comparar o concreto com o acréscimo do grafeno ou de seus derivados, viabilidade, pós e contras. (3) Através da característica elétricas, uma das características a quem mais chama atenção, evidenciar a possibilidade da utilização do grafeno na construção de rodovias inteligentes capaz de carregar carros elétricos em movimento através de indução de forma mais rápida.

A presente pesquisa foi, portanto, considerada satisfatória, pois os resultados existentes sobre o uso do grafeno como reforço para o Polipropileno são positivos permitindo que o seu uso alcance as diferentes áreas da construção civil, inclusive na construção de estradas e ciclovias, e linearmente incentivar a reciclagem de materiais PP, possibilitando através dessa afirmativa, uma engenharia mais sustentável.

\title{
REFERENCIAS BIBLIOGRÁFICAS
}

ALDO J. G. ZARBIN, Quím. Nova vol.30 no.6 São Paulo Nov./Dec. 2007

\section{ALDO J. G. ZARBIN; Marcela M. Oliveira: NANOESTRUTURAS DE CARBONO (NANOTUBOS, GRAFENO): QUO VADIS?, 2013}

\author{
ALEXANDRE FORMIGONI, Reciclagem de PET no Brasil, UNESP, 2012
}

AZEVEDO, Daniela. Físicos descobrem nova propriedade do grafeno: magnetismo. Mais Tecnologia, Disponível em <https://www.maistecnologia.com/fisicos-descobrem-novapropriedade-do-grafeno-magnetismo/.> Acesso em io de outubro de 2020.

ANDERSON CANSANA ET AL, projeto de produção do grafeno por microesfoliação mecânica do grafite pirolítico fortemente orientado. 2019 
BOCCATO, VERA REGINA*, metodologia da pesquisa bibliográfica na área odontológica e o artigo científico como forma de comunicação. Revista de Odontologia da Universidade Cidade de São Paulo, 2006

BORSCHIVER, S.; GUIMARÃES, M. J. O. C.; SANTOS, T. N.; SILVA, F. C.; BRUM, P. R. C.. Patenting in nanotechnology: study of the sector of nanostructured polymeric materials Polymers: science and technology v.15, n.4, p.245-248, 2005.

DOI:,http://doi.org/I0.1590/So104-I4282005000400007

BROGNOLI, R. - Dossiê técnico, SENAI/RS, Junho (2006).

CARLOS A. GUERRERO SALAZAR ET AL, Composites de poli-(tereftalato de etilen glicol), PET, con óxido de grafeno reducido, rGO, 2019.

CARNEIRO, Luiz Antonio Vieira; TEIXEIRA, Ana Maria Abreu Jorge. Propriedades e características dos materiais compósitos poliméricos aplicados na Engenharia de Construção. Revista Militar de ciência e tecnologia, 2008.

CARUSO, Ricardo. Empreiteiras (mais) desesperadas: vem aí as estradas de plástico. BAND. Disponível em <http://autoetecnica.band.uol.com.br/empreiteiras-maisdesesperadas-vem-ai-as-estradas-de-plastico/.> Acesso em I8 de setembro de 2020.

CARVALHO, Caio. «Grafeno: conheça o material que vai revolucionar a tecnologia do futuro». Canaltech. Consultado em 22 de setembro de 2020

CORSO, M.; AlbuQUERQUE, A. C. D.; AMARO, L. P.; BERTO, L. K.; FAVARO, S. L.; IMAI, H. E.; CARDOSO, A. P.; YAMAGUCHI, N. U.; REZENDE, L. C. S. H.. Graphene oxide synthesis for composite material preparation. Revista Ibero Americana de Ciências Ambientais v.Io, $\quad$ n.I, $\quad$ p.157-I66, 2019 . DOI: http://doi.org/10.6oo8/CBPC2179-6858.2019.001.0o13

DAMODAR, R.A., SWAMINATHAN, T., YOU, SHENG-JIE, Degradation of synthetic dyes in a novel IRTPR. J. Environ. Eng. Manag. 19, I07eII2. 2009

EDA, G.; FANCHINI, G.; CHHOWALLA, M.. Large-area ultrathin films of reduced graphene oxide as a transparent and flexible electronic material. Nature Nanotechnology v.3, n.5, p.270-274, 2008.

DOI:http://doi.org/Io.1038/nnano.2008.83

FERNANDES, Silvio Soares; DIACENCO, Adriana Amaro. ORIGEM DO PVC E SEU PROCESSO DE TRANSFORMAÇÃO, Centro Universitário de Itajubá - MG, 
FIEDLER, André. UCS inaugura maior fábrica de grafeno da América Latina atingindo metas de produção. Pioneiro Economia, Disponível em 〈http://pioneiro.clicrbs.com.br/rs/economia/noticia/2020/o4/ucs-inaugura-maiorfabrica-de-grafeno-da-america-latina-atingindo-metas-de-producao- $12320846 . \mathrm{html}>$ Acesso I2 de outubro de 2020

HACK, RENATA. Nanocompósitos poliméricos multifuncionais reforçados com grafeno, (2013)

HERNÁNDEZ, Mayra Iveth Ilamas. COMPORTAMIENTO ELÁSTICO Y MORFOLÓGICO DE COMPOSITES POLIPROPILENO/GRAFENO, UNIVERSIDAD AUTÓNOMA DE NUEVO LEÓN, 2014

J. E. D.VIEIRA ; E. O. VILAR2*, Grafeno: Uma revisão sobre propriedades, mecanismos de produção e potenciais aplicações em sistemas energéticos, 2017.

J.A RAYAS ET AL, Medición del módulo de Young en el hule látex usando ESPI, 2003

LARA DE SOUZA SOLETTI ET AL, síntese de composto de areia e grafeno nanoestruturado para remoção de chumbo em água, encontro internacional de produção científica, 2019

MANDARINO, Diego. Grafeno poderá ser empregado na pintura de navios e indústria de plásticos. Pioneiro Economia, Disponível em <http://pioneiro.clicrbs.com.br/rs/economia/noticia/2020/o2/grafeno-podera-serempregado-na-pintura-de-navios-e-industria-de-plasticos-12188245.html> Acesso 12 de outubro de 2020

MANO, Eloisa Biasotto, POLÍMEROS COMO MATERIAIS DE ENGENHARIA, Ed. Edgard Blücher Ltda, 199I

MLA style: The Nobel Prize in Physics 2010. NobelPrize.org. Nobel Media AB 2020. Mon. 21 Sep 2020. https://www.nobelprize.org/prizes/physics/2010/summary/

MONTENEGRO, Ricardo Sá Peixoto; SERFATY, Moysés Elias. ASPECTOS GERAIS DO POLIESTIRENO, Biblioteca BNDES, 2002

MOREIRA, Anabela Mendes Materiais de construção I, Instituto Politécnico de tomar, 2009

NEGRETI, Maria A. de Paula. OBTENÇÃO E CARACTERIZAÇÃO DE COMPÓSITOS POLIMÉRICOS COM ÓXIDO DE GRAFENO REDUZIDO, Escola Politécnica da Universidade de São Paulo. 2016 
NUNES, L. R.; RODOLFO, A. Jr.; ORMANJI, “Tecnologia do PVC”, São Paulo: ProEditores / Braskem, 2002.

OLIVEIRA, WEMERSON, Uma visão geral sobre o grafeno, 2017

PAOLO BOLLELLA ET AL, Beyond graphene: Electrochemical sensors and biosensors for biomarkers detection; 2016

OTA, Waldyr Naoki. Análise de compósitos de polipropileno e fibras de vidro utilizados pela indústria automotiva nacional, UNIVERSIDADE FEDERAL DO PARANÁ, 2004

POTTS, J. R.; DREYER, D. R.; BIELAWSKI, C. W.; RUOFF, R. S. Graphene-based polymer nanocomposites. Polymer $52,201 \mathrm{I}$

QUEVEDO, RENATA TOMAZ, Polímeros, Faculdades Anhanguera 2016.

Revista Techne, http://cobec.com.br/principais-tipos-de-plasticos-usados-nos-produtose-sistemas- construtivos/ Consultado 24/10/2020.

ROMÃO, Wanderson; Márcia A. S. Spinacé; Marco-A. De Paol, Poli(tereftalato de etileno), PET: uma revisão sobre os processos de síntese, mecanismos de degradação e sua reciclagem, Instituto de Química, Unicamp, 2009

SALOMON DV. Como fazer uma monografia. ıra ed. São Paulo: Martins Fontes; 2004.

SCHNIEPP, H. C.; LI, J-L.; MCALLISTER, M. J.; SAI, H.; HERRERA-ALONSO, M.; ADAMSON, D. H.; PRUD'HOMME, R. K.; CAR, R.; SAVILlE, D. A.; AKSAY, I. A. Functionalized single graphene sheets derived from splitting graphite oxide. Journal of Physical Chemistry B iı (2006), 8535-8539

SEM AUTOR. Grafeno: 7 aplicações na construção civil. Plantas de casas, disponível em 〈https://plantasdecasas.com/grafeno-6-aplicacoes-na-construcao-civil/.> Acesso em 26 de setembro de 2020 .

SEM AUTOR. Nanotecnologia. Centro de Tecnologias estratégicas do Nordeste, Disponível em 〈https://www.cetene.gov.br/index.php/area-de-atuacao/nanotecnologia.> Acesso em I6 De setembro de 2020.

SEM AUTOR. Conheça os tipos de plásticos. Ecycle, Disponível em 〈https://www.ecycle.com.br/706-tipos-de-plasticos> Acesso em o9 de novembro de 2020.

SILVA MELO et al. Nanotecnologia aplicada ao concreto: efeito da mistura de nanotubos de carbono em matrizes de cimento portland. Belo Horizonte: UFMG, 2009. Dissertação (Mestrado de Construção Civil) Escola de Engenharia, Universidade Federal de Minas Gerais, Belo Horizonte, 2009. 
SILVA, Rita Isabel Sousa e, Influência do teor de grafeno nas propriedades do polipropileno isotático, Faculdade de Ciência e Tecnologia Universidade de Coimbra. 2017

SPINACÉ, Márcia A. S.; PAOLI, Marco A. de; A tecnologia da reciclagem de polímeros, Quím. Nova vol.28 no.r São Paulo Jan./Feb. 2005

SOUSA, Rafaela. "Primeira Revolução Industrial"; Brasil Escola. Disponível em: https://brasilescola.uol.com.br/geografia/primeira-revolucao-industrial.htm. Acesso em I4 de setembro de 2020 . 